\title{
Identification of a Nuclear Factor Kappa B-dependent Gene Network
}

\author{
Bing Tian and Allan R. Brasier \\ Department of Medicine and the Sealy Center for Molecular Sciences, The University of Texas \\ Medical Branch, Galveston, Texas 77555-1060
}

\begin{abstract}
Nuclear factor-kappa B (NF- $\kappa$ B) is a highly inducible transcription factor that plays an important role in the hepatic acute-phase response, innate/adaptive immunity, and cellular survival through the induction of genetic networks. The major transcriptional-activating species Rel A-NF- $\kappa \mathrm{B}$ is a cytoplasmic complex whose nuclear translocation is controlled by its association with a family of inhibitory proteins, termed I $\kappa \mathrm{Bs}$. Activation of NF- $\kappa \mathrm{B}$ results in the targeted proteolysis of $\mathrm{I} \kappa \mathrm{B}$, releasing NF- $\kappa \mathrm{B}$ to enter the nucleus and bind to specific sequences in target promoters. Because the genomic actions of NF- $\kappa \mathrm{B}$ are influenced by the stimulus applied and the promoter context/chromatin structure in which it binds, the spectrum of NF- $\kappa \mathrm{B}$-regulated genes has not been elucidated. We have begun to address this question, exploiting a tightly regulated cellular system expressing a nondegradable $\mathrm{I} \kappa \mathrm{B} \alpha$ mutant that completely inhibits NF- $\kappa \mathrm{B}$ action. High-density oligonucleotide microarrays were used to identify genetic responses in response to complex biological stimuli (viral replication) in the presence and absence of NF- $\kappa$ B. Using statistical and informatics tools, we identified two groups of NF- $\kappa \mathrm{B}$-dependent genes with distinct expression profiles: 1) a group with high constitutive expression whose expression levels fall in response to viral exposure and constitutive mRNA expression increases from NF- $\kappa$ B blockade, and 2) a group where constitutive expression was very low (or undetectable) and, after stimulation, expression levels strongly increased. In this group, NF- $\kappa \mathrm{B}$ blockade inhibited the viral induction of genes. This latter cluster includes chemokines, transcriptional regulators, intracellular proteins regulating translation and proteolysis, and secreted proteins (e.g., complement components, growth factor regulators). These data reveal complexity in the genetic response to NF- $\kappa \mathrm{B}$ and serve as a foundation for further informatics analysis to identify genetic features common to up- and downregulated NF- $\kappa \mathrm{B}-$ dependent promoters.
\end{abstract}

\section{Introduction}

The mechanisms controlling RNA polymerase II-dependent gene expression in eukaryotes have been investigated intensively over the past several decades. From this work, it is widely accepted that transcriptional initiation is the primary mechanism controlling gene expression in response to tissue specific-, developmental-, and hormonal-induced cellular signaling (McKnight and Yamamoto, 1992). Transcriptional activation is a multistep process initiated by sequence-specific proteins binding to upstream regulatory sites of DNA flanking 
transcribed regions of a gene. In highly inducible gene promoters, enhanceosomes - nucleoprotein complexes assembled on inducible enhancer sequences in the regulatory regions - allow for multiple, intracellular signaling cascades to modulate target gene expression (Thanos and Maniatis, 1995). Formation of the enhanceosome is initiated by the binding of sequence-specific transcription factors and results in the cooperative binding of accessory chromatin-remodeling proteins, nuclear coactivators, kinases, and/or histone acetylases into the nucleoprotein complex. The presence of chromatin-remodeling factors induces formation of an activated preinitiation complex that, in turn, controls DNA-dependent RNA polymerase II activity and subsequent gene expression. Although the basic biochemistry of preinitiation complex formation and the identification of how signaling molecules control transcription factor have resulted from the study of promoters on an individual level, the spectrum of genes controlled by specific signaling pathways within the context of a complex biological stimulus has not been explored systematically.

The development and application of high-density microarrays is an enabling technology that allows global understanding of genome-wide changes in cellular mRNA abundance in response to specific stimuli (Tavazoie et al., 1999; Bussemaker et al., 2001; Berman et al., 2002). However, as it is commonly used, mRNA profiling is a correlational tool that records patterns of gene expression in response to specific cellular perturbations. Although these studies provide new insight into cellular responses, allowing the identification of genes controlled by a stimulus not previously considered, little mechanistic information arises on the interaction of downstream signaling pathways in controlling specific subsets of genes. Herein, we describe our approach to experimentally identify genetic networks under inducible transcription factor control using mRNA profiling. We have chosen the highly inducible transcription factor, NF- $\kappa \mathrm{B}$, and sought to identify its role in response to a complex biological stimulus (viral replication).

\section{A. NF- $\kappa$ B AS AN INDUCIBLE TRANSCRIPTIONAL REGULATOR}

$\mathrm{NF}-\kappa \mathrm{B}$ is a ubiquitously expressed, highly inducible transcription factor that plays an important role in the hepatic acute-phase response, innate and adaptive immunity, and cellular survival through the induction of genetic networks (Barnes and Karin, 1997; Karin, 1999). Composed of five distinct gene products related by a common $\mathrm{NH}_{2}$-terminal Rel homology domain, the NF- $\kappa \mathrm{B}$ family is divided into two functionally distinct groups that freely heterodimerize. The first group consists of members translated as mature proteins that bind DNA weakly and contain potent $\mathrm{COOH}$-terminal transcriptional activation domains (Rel A and c-Rel). The second group has members encoded by large precursor proteins that are proteolytically processed into small $(\approx 50 \mathrm{kDa})$ DNA-binding subunits with strong DNA-binding activity and weak transcriptional activation potential (p105/ 
NF- $\kappa$ B1 and p110/NF- $\kappa$ B2) (reviewed in Siebenlist et al., 1994; Baldwin, 1996; Barnes and Karin, 1997). The subunit composition of the NF- $\kappa \mathrm{B}$ complex influences its subcellular localization, transactivation potential, and mode of regulation. For example, homodimers of NF- $\kappa \mathrm{B} 1$ are primarily nuclear proteins with weak transactivation potential. They are activated by phorbol myristate acid (PMA) and peptide hormones to weakly activate gene transcription (Jamaluddin et al., 2000). Conversely, the prototypical NF- $\kappa \mathrm{B}$ complex, composed of $50 \mathrm{kDa}$ $\mathrm{NF}-\kappa \mathrm{B} 1-65 \mathrm{kDa}$ Rel A heterodimers, is primarily cytoplasmic. The complex is regulated by its association with a family of inhibitors, I $\kappa \mathrm{Bs}$, whose members bind and specifically inactivate Rel A by masking its nuclear-localization sequence and preventing nuclear entry (Henkel et al., 1993; reviewed in Beg and Baldwin, 1993; Han et al., 1997). In response to cellular stimulation by cytokines and pathogens, Rel A-NF- $\mathrm{B} 1$ enters the nucleus, where it becomes a potent transactivator.

The mechanism controlling nuclear translocation of Rel A-NF- $\kappa \mathrm{B} 1$ has been intensively investigated. Rel A-NF- $\kappa \mathrm{B} 1$ activation requires inducible proteolysis of the $\mathrm{I} \kappa \mathrm{B}$ inhibitors, a process initiated by $\mathrm{I} \kappa \mathrm{B} \alpha$ phosphorylation (Brown et al., $1995)$. Intracellular NF- $\kappa \mathrm{B}$-activating signals converge on the multiprotein cytoplasmic I $\kappa \mathrm{B}$ kinase complex (IKK), a complex that phosphorylates I $\kappa \mathrm{B}$ on two serine residues $\left(\mathrm{Ser}^{32}\right.$ and $\mathrm{Ser}^{36}$ ) in its $\mathrm{NH}_{2}$-regulatory domain (reviewed in Karin, 1999). The IKK is a multiprotein, cytosolic kinase of $\approx 700 \mathrm{kDa}$, composed of catalytic basic helix-loop-helix-containing kinases, IKK $\beta$ and IKK $\alpha$, and a regulatory subunit, IKK $\gamma$, required for coupling IKK to upstream activating kinases (Karin,1999; Poyet et al., 2000; Zhang et al., 2000). The pathways for how the cytokines, interleukin-1 (IL-1) and tumor necrosis factoralpha $(\mathrm{TNF} \alpha)$, activated $\mathrm{NF}-\kappa \mathrm{B}$ through the IKK have been extensively investigated. IL-1 and TNF $\alpha$ cytokine receptors are single-pass, transmembrane receptors lacking intrinsic kinase activity. Upon binding ligand, the receptors form trimeric structures, resulting in intracellular aggregation of the cytoplasmic signaling domains. This results in the recruitment of a submembranous signaling complex activating IKK; in the case of the IL-1 signaling pathway, the signal adapters include MyD88, IL-1 receptor-associate kinase (IRAK), and the TNF receptor-associated factor 6 (TRAF6) (Cao et al., 1996). TRAF6 is required for coupling the activated IL-1 receptor to the IKK; recently, it was shown that TRAF6 is ligated by unique lysine 63-linked polyubiquitin chains, a modification that is required to activate the downstream MAPKK kinase, TGF $\beta$-associated kinase (TAK1) (Ninomiya-Tsuhi et al., 1999; Wang et al., 2001). TAK1, in turn, phosphorylates the first committed step in NF- $\kappa \mathrm{B}$ activation, the NF- $\kappa \mathrm{B}$-inducing kinase (NIK), resulting in IKK $\beta$ phosphorylation and IKK activation (Malanin et al., 1997; Wang et al., 2001). In TNF signaling, TNF receptor-associated death domain (TRADD), TRAF2, and receptor-interacting protein (RIP) constitute the submembranous signaling complex (Hsu et al., 1996; Zhang et al., 2000). Here, 
the RIP kinase plays an indispensable role in IKK activation, as targeted disruption of RIP abolishes NF- $\kappa \mathrm{B}$ activation (Kelliher et al., 1998). RIP recently has been shown to recruit the IKK signalsome to the TNF receptor I by binding IKK $\gamma$, directly recruiting the cytosolic IKK to it (Zhang et al., 2000). IKK $\alpha$ and IKK $\beta$ then are phosphorylated, releasing the activated IKK complex back into the cytosolic fraction (Poyet et al., 2000; Zhang et al., 2000).

In the IKK complex, the catalytic IKK $\beta$ subunit is largely thought to be responsible for the site-specific serine phosphorylation of $\mathrm{I} \kappa \mathrm{B} \alpha$ in its $\mathrm{NH}_{2}$ terminal regulatory domain, resulting in the first rate limiting in the process of NF- $\kappa$ B activation. PhosphoI $\kappa$ B is specifically bound by the Skp1-cullin-F-boxtype E3 ubiquitin ligase, E3RS, initiating I $\kappa \mathrm{B}$ ubiquitination and proteolysis through the proteasome (Brown et al., 1995; Karin, 1999; Karin and Ben Neriah, 2000). A parallel pathway important in viral infection that produces $I \kappa B$ degradation through cytoplasmic calpains also has been identified (Jamaluddin et al., 1998; Han et al., 1999b). Following I $\kappa \mathrm{B}$ proteolysis, liberated NF- $\kappa \mathrm{B}$ enters the nucleus to activate target gene transcription.

\section{B. MECHANISMS FOR NF- $\kappa$ B-DEPENDENT TRANSACTIVATION}

Liberated, cytoplasmic NF- $\kappa \mathrm{B}$ rapidly enters the nucleus through specific nuclear-importing signals located in its $\mathrm{NH}_{2}$-terminal Rel homology domain and bind to specific DNA sites in the regulatory regions of inducible promoters. A nonbiased polymerase chain reaction (PCR)-binding site-selection assay has elucidated the high-affinity binding sites for the homodimeric NF- $\kappa \mathrm{B} 1$ (p50) and Rel A (p65) proteins as 5'-GGGGATYCC-3' and 5'-GGGRNTTTCC-3', respectively (Kunsch et al., 1992). These binding sites match the empirically defined consensus binding sites of acute-phase reactant (angiotensinogen) (Brasier et al., 1996), cytokine (IL-8) (Garofalo et al., 1996; Brasier et al., 1998), and chemokine (RANTES, an acronym for regulated upon activation, normally T-cell expressed and presumably secreted) (Casola et al., 2000b) promoters.

Promoter-bound NF- $\kappa \mathrm{B}$ activates transcription from inducible regulatory elements through the assembly of larger nucleoprotein complexes termed enhanceosomes. Pioneering studies on the interferon (IFN)- $\beta$ promoters have revealed that inducible transcriptional regulation is a multistep process involving the cooperative assembly of architectural (DNA remodeling), sequence-specific transcription factors, and coactivator/bridging proteins on a target enhancer. The phenomenon of binding cooperativity allows highly inducible genes to be expressed in the setting of limiting concentrations of transcription factors (reviewed in Carey, 1998). The IFN- $\beta$ promoter contains a virus-inducible enhancer with three essential domains, termed positive regulatory domains (PRDs). In vitro, PRDII binds NF- $\kappa \mathrm{B}$, PRDIV binds activating transcription factor (ATF)-2/c-Jun, and PRDIII-I binds interferon regulatory factor-1 (IRF-1). 
Gene-transfer studies have shown that stimulus-specific activation of IFN $\beta$ is accomplished through initial recruitment of the architectural protein high-mobility group (HMG) $\mathrm{I}(\mathrm{Y})$, a minor groove DNA-binding protein recognizing AT-rich elements contained in the PRDII and PRDIV domains (Yie et al., 1999b). HMG I(Y) binding bends the DNA into a conformation that allows cooperative binding of the transcription factors NF- $\kappa$ B and ATF-2/c-Jun to their respective motifs in PRDII and PRDIV domains. Additional protein-protein interactions recruit IRF, general transcription factors, and the coactivator/pol holoenzyme cyclic AMP response binding protein (CBP)/polII into the complex (Munshi et al., 1998). Additional modifications to DNA and histones result in an increased rate of preinitiation complex formation, allowing multiple rounds of transcription and reinitiation of the IFN $\beta$ transcripts (Yie et al., 1999b). Once assembled, the enhanceosome is an extremely stable nucleoprotein structure through protein-protein and protein-DNA interactions, resistant to oligonucleotide competition and detergent treatment (Yie et al., 1999a).

We have made similar observations on the NF- $\kappa \mathrm{B}$-dependent, highly inducible IL-8 and RANTES promoters (Casola et al., 2000a,b). For example, in the case of IL-8, although NF- $\kappa$ B is absolutely required for inducible transcriptional activation (mutation of the NF- $\kappa \mathrm{B}$-binding site renders the promoter inert to any stimulation), an additional upstream site containing the IRF-1/7 complex is required for activation of the gene (Casola et al., 2000a). Interestingly, genetransfer experiments also demonstrate that the requirement for "ancillary" cis elements (e.g., the IRF-binding site in viral stimulation) is distinct from those required for activation by TNF (Casola et al., 2000a). Together, these data indicate that the actions of NF- $\kappa \mathrm{B}$ are determined by presence of ancillary binding sites in the target promoter and constrained by the stimulus applied.

Enhanceosome formation involves coactivator recruitment, proteins required for control of core promoter activity at a distance. Coactivators are non-DNA binding proteins that allow transcription factors to couple with the basal transcriptional apparatus and induce chromatin remodeling (Blobel, 2000). Chromatin remodeling is an active process occurring as a first step in promoter activation, known as "de-repression" (Jones and Kadonaga, 2000). This adenosine triphosphate (ATP)-dependent event is mediated through enzymatic (histone acetyltransferase, HAT) activity contained in the p300/CBP and p300/CBP-associated factor ( $\mathrm{p} / \mathrm{CAF}$ ) coactivators. HATs acetylate basic residues on core histones, weakening their binding, thereby allowing other components of the transcriptional machinery to access the target promoter (Korzus et al., 1998; Blobel, 2000). Although there is redundancy in coactivator activity, certain types of coactivators are known to preferentially mediate genomic actions of transcription factor classes. Of relevance here, Rel A recruits the p300/CBP coactivator through interaction with its $\mathrm{COOH}$ transactivation domain (Perkins et al., 1997; Wadgaonkar et al., 1999). Antibody-injection experiments have shown that the 
HAT activity of the related coactivator $\mathrm{p} / \mathrm{CAF}$ is also important in NF- $\kappa \mathrm{B}$ transactivation. Moreover, the mechanism for coactivator recruitment appears to be distinct between NF- $\kappa \mathrm{B} 1$ and Rel A-complexed DNA-binding sites. The steroid receptor coactivator 1 (SRC-1), originally thought to be a specific nuclear receptor coactivator, transactivates NF- $\kappa \mathrm{B} 1$ binding sites in synergy with $\mathrm{p} 300 /$ CBP (Na et al., 1998). SRC-1 specifically binds NF- $\kappa$ B 1 but not Rel A (Na et al., 1998), strongly suggesting that alternative pathways for coactivator recruitment and promoter activation are utilized, depending on the composition of the NF- $\kappa \mathrm{B}$ complexes assembled on a specific site. The individual roles of the various coactivators have yet to be determined.

Some recent intriguing work in macrophages has indicated that chromatin organization controls the temporal access of NF- $\kappa \mathrm{B}$ to its target promoters (Saccani et al., 2001). Chromatin ImmunoPrecipitation (ChIP) assays involve the specific immunoprecipitation of genes reversibly cross-linked to NF- $\kappa \mathrm{B}$ that are detected by PCR. Using ChIP assays on lipopolysaccharide-stimulated macrophages, two distinct waves of NF- $\kappa \mathrm{B}$ recruitment to target genes were observed. NF- $\kappa \mathrm{B}$ was recruited rapidly (i.e., within 20 minutes of stimulation) to the $\mathrm{I} \kappa \mathrm{B} \alpha$, MIP-2, and manganese superoxide dismutase gene promoters, constituting the "constitutively and immediately accessible" (CIA) genes. CIA genes are stably associated with acetylated histone H4. Conversely, a second wave of NF- $\kappa \mathrm{B}$ recruitment was observed on the RANTES, MCP, and IL-6 promoter, constituting the "regulated late accessibility" (RLA) genes. The RLA genes were not constitutively bound by acetylated histone $\mathrm{H} 4$ but were induced to bind acetylated $\mathrm{H} 4$ prior to detectable NF- $\kappa \mathrm{B}$ recruitment (Saccani et al., 2001). Genes in the RLA group, although activated by NF- $\kappa \mathrm{B}$, apparently had to undergo chromatin remodeling event prior to NF- $\kappa \mathrm{B}$ binding. The mechanisms and pathways controlling chromatin remodeling are incompletely understood; however, these workers observed that recruitment of activator protein-1 (AP-1) complexes temporally preceded that of NF- $\kappa \mathrm{B}$, suggesting that AP-1 may be inducing chromatin remodeling in a subset of RLA promoters. These observations suggest unanticipated complexity in NF- $\kappa \mathrm{B}$ action by regulating its accessibility to target promoters to certain chromatin domains.

\section{Approach for Experimental Identification of Genetic Networks Downstream of NF- $\kappa \mathrm{B}$}

Although NF- $\kappa \mathrm{B}$-binding sites now can be identified with some degree of reliability, it is clear that the actions of NF- $\kappa \mathrm{B}$ are controlled by the promoter context in which it binds, the stimulus applied, and the chromatin structure of the target promoter. Our general strategy was to employ a nonbiased, high-throughput methodology to identify genes downstream of NF- $\kappa \mathrm{B}$ in response to a complex biological stimulus, schematically diagrammed in Figure 1. We rea- 


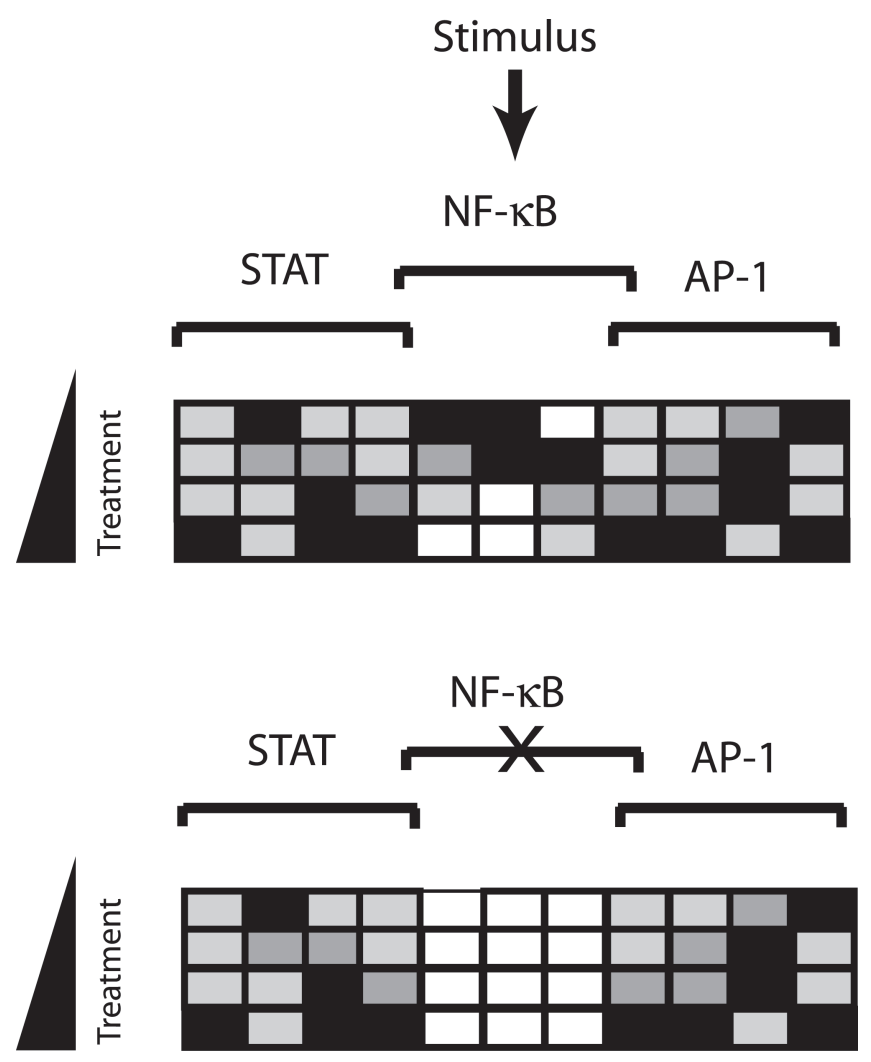

FIG. 1. Overview of high-throughput microarray strategy. Schematic overview of approach to identify NF- $\kappa \mathrm{B}$-dependent gene networks in response to a complex biological stimulus. Upstream signals activate downstream transcription factors such as NF- $\kappa \mathrm{B}$, signal transducer of activator of transcription (STAT), and activator protein-1 (AP-1). These, in turn, control the expression of overlapping gene networks whose expression is quantified by high-density microarray analysis. The approach compares gene-expression profiles under two conditions: one where NF- $\kappa \mathrm{B}$ can be activated (top), the other when NF- $\kappa$ B cannot (bottom).

soned that comparing high-density oligonucleotide arrays on control or stimulated cells in the absence or presence of a specific inhibitor of NF- $\kappa \mathrm{B}$ activation would identify those genes downstream of NF- $\kappa \mathrm{B}$.

For this approach, we required a cell that could be manipulated to express a dominant-negative NF- $\kappa$ B inhibitor. Because NF- $\kappa$ B is required for normal cell growth and survival (NF- $\kappa$ B Rel A deficiency in mice is embryonic lethal due to massive hepatic apoptosis) (Beg et al., 1995) and adenovirus-mediated transduction could activate signaling pathways in infected cells, we developed a tetracycline-regulated cell system (Tet-Off) (Gossen and Bujard, 1992). This cell 
system expresses the nondegradable, epitope-tagged $\mathrm{I} \kappa \mathrm{B} \alpha\left(\mathrm{I} \kappa \mathrm{B} \alpha \mathrm{Ser}^{32} \mathrm{Ala} /\right.$ $\mathrm{Ser}^{36}$ Ala, termed FLAG-I $\kappa \mathrm{B} \alpha$ Mut) under control of the Tet Operator sequences (TetO). FLAG-I $\kappa \mathrm{B} \alpha$ Mut contains site mutations in the serine phosphoacceptor sites of IKK $\beta$ and functions as a potent dominant-negative inhibitor of NF- $\kappa \mathrm{B}$ activation (Thomas et al., 1998b). In the Tet-Off stable cells, we were able to inhibit expression of FLAG-I $\kappa \mathrm{B} \alpha$ Mut during the selection process by including low concentrations of doxycycline (Dox) in the selection medium. Dox binds the tetracycline transactivator (tTA) and inhibits its binding. Upon Dox withdrawal, tTA binds DNA (TetO) and activates expression of the target gene (Figure 2). Using this strategy, we successfully isolated stable clonal cell lines where FLAG-I $\kappa \mathrm{B} \alpha$ Mut expression was induced strongly after Dox withdrawal from the culture medium. For example, in Figure 3, a western immunoblot of cytoplasmic extracts was performed using antibody recognizing the FLAG
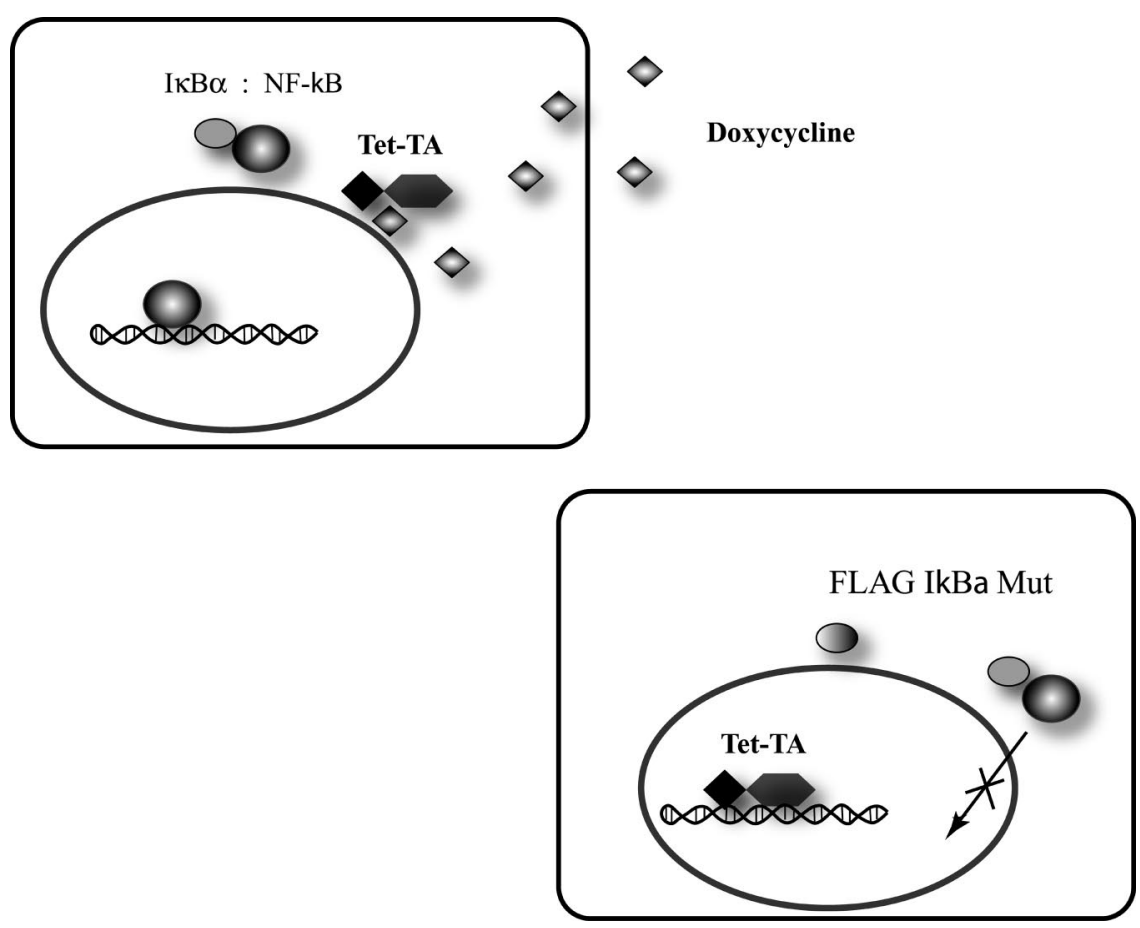

FIG. 2. Schematic view for regulated inhibition of NF- $\kappa$ B action. Inhibition of NF- $\kappa B$ is accomplished by a dual-selection procedure where the tetracycline-regulated transactivator (Tet-TA) regulates expression of the nondegradable FLAG-I $\kappa \mathrm{B} \alpha$ Mut inhibitor under control of the tetracycline operator. Tet-TA cannot bind DNA in the absence of tetracycline (doxycycline, Dox) and FLAG- $\mathrm{I} \kappa \mathrm{B} \alpha$ Mut is not expressed at high levels. When Dox is withdrawn from the culture medium, FLAG-I $\kappa \mathrm{B} \alpha$ Mut is expressed, inhibiting NF- $\kappa \mathrm{B}$ nuclear translocation. 


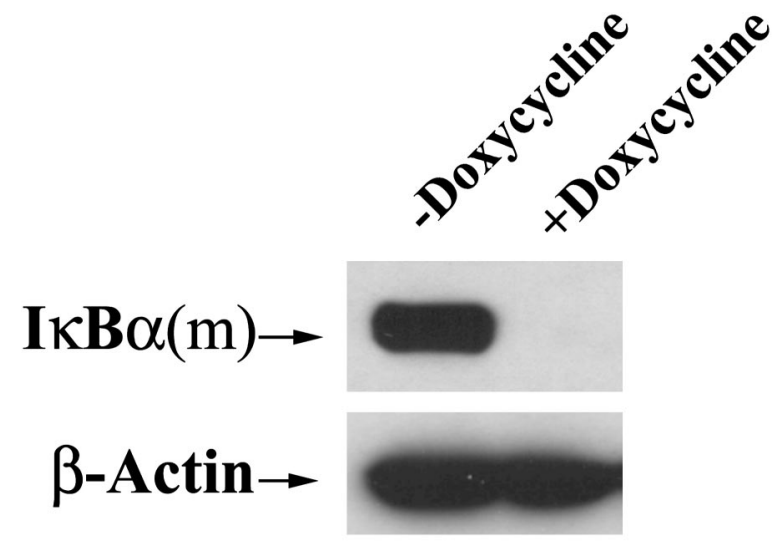

FIG. 3. Regulation of FLAG-I $\kappa \mathrm{B} \alpha$ Mut expression by Dox. I $\kappa \mathrm{B} \alpha$ Mut-expressing cells isolated in the presence of Dox $(2 \mu \mathrm{g} / \mathrm{ml}$ in growth medium) were transferred to Dox-free medium and cultured for 7 days. Cytoplasmic extracts were prepared and $150 \mu \mathrm{g}$ fractionated on 10\% SDS-PAGE (sodium dodecyl sulfate-polyacrylamide gel electrophoresis) and subjected to western immunoblot using anti-FLAG M2 monoclonal antibody-peroxidase conjugate. After FLAG detection, the immunoblot was reprobed for $\beta$-actin as a loading control (bottom). FLAG-I $\kappa \mathrm{B} \alpha$ Mut is strongly expressed in the absence of Dox. [Data adapted from Tian B, Zhang Y, Luxon BA, Garofalo RP, Casola A, Sinha M, Brasier AR 2002 Identification of NF- $\kappa$ B dependent gene networks in respiratory syncytial virus-infected cells. J Virol 76:6800-6814.]

epitope tag of the FLAG-I $\kappa \mathrm{B} \alpha$ Mut fusion protein. Highly inducible and tightly regulated expression of FLAG-I $\kappa \mathrm{B} \alpha$ Mut was seen with early passages after stable clones were isolated. Importantly, in the short durations used for expression and stimulation, these cells did not have detectable differences in spontaneous or viral-induced apoptosis (Tian et al., 2002). FLAG-I $\kappa \mathrm{B} \alpha$ Mut expression potently inhibited NF- $\kappa \mathrm{B}$-dependent transcription in response to the prototypical $\mathrm{NF}-\kappa \mathrm{B}$-activating cytokine, TNF $\alpha$, and in response to respiratory syncytial virus (RSV) infection (Figure 4). Figure 4A shows an electrophoretic gel mobility-shift assay (EMSA) of nuclear extracts taken from cells stimulated with TNF in the absence of the dominant-negative inhibitor ( + Dox) vs. those expressing the dominant-negative inhibitor (-Dox). In these cells, TNF is a potent inducer of Rel A NF- $\kappa$ B1 binding (Garofalo et al., 1996; Brasier et al., 1998; Tian et al., 2002). (These sequence-specific binding complexes previously have been shown to be subunit specific using supershift assays and microaffinity isolation.) Figure 4B shows a western immunoblot of cytoplasmic extracts from the same cells (as used in the EMSA in Figure 4A) staining with antibody that recognizes $I \kappa \mathrm{B} \alpha$. Expression of the dominant-negative $\mathrm{I} \kappa \mathrm{B} \alpha$ (the slower migrating band) is induced strongly in the absence of Dox at levels comparable to endogenous $\mathrm{I} \kappa \mathrm{B} \alpha$. Similarly, although endogenous $\mathrm{I} \kappa \mathrm{B} \alpha$ is degraded proteolytically by TNF, 


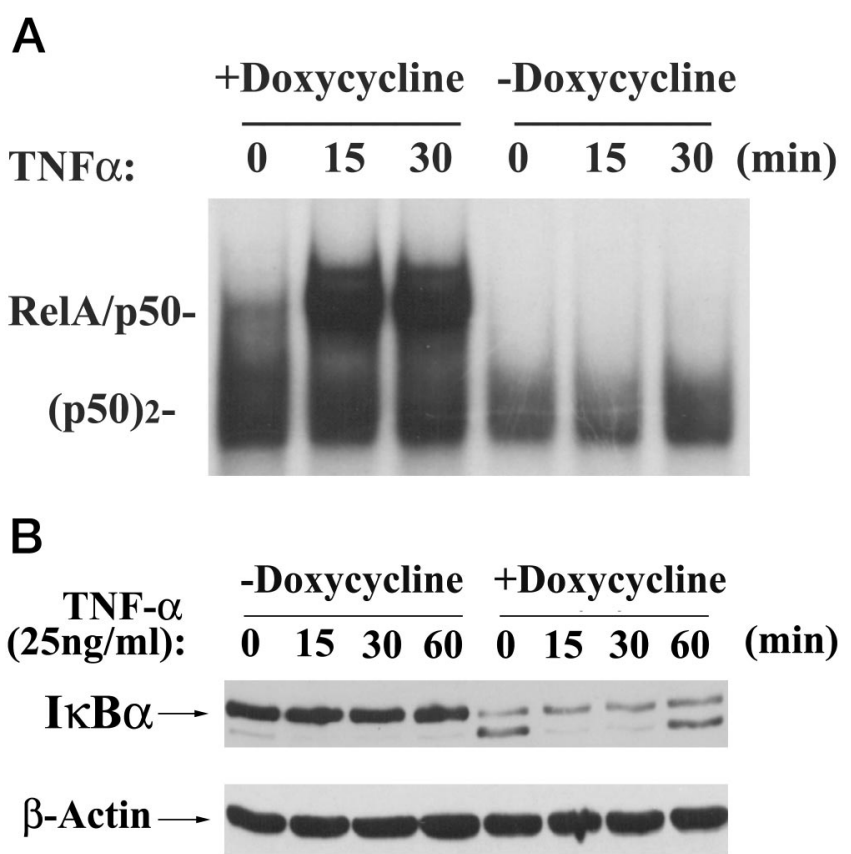

FIG. 4. Dox-dependent inhibition of NF- $\kappa \mathrm{B}$ activation and $\mathrm{I} \kappa \mathrm{B} \alpha$ proteolysis. (A) Time course of NF- $\kappa$ B binding in electrophoretic mobility shift assay (EMSA). Sucrose cushion-purified nuclear extracts were prepared from tumor necrosis factor alpha (TNF $\alpha)$-stimulated cells cultured in the absence or presence of Dox for the time indicated. EMSA was performed using the ${ }^{32} \mathrm{P}$-labeled acute-phase response element, wild-type (APRE WT) duplex oligonucleotide probe (Brasier et al., 2001). The complexes were fractionated on $6 \%$ native polyacrylamide gels; an autoradiographic exposure is shown. The relative migration of the RelA/NF- $\kappa \mathrm{B} 1$ ("p50") heterodimer and the p50 homodimer (p50) $)_{2}$ complexes are indicated (Jamaluddin et al., 1998). Expression of FLAG-I $\kappa \mathrm{B} \alpha$ Mut completely inhibits RelA/NF- $\kappa \mathrm{B} 1$ binding. (B) Resistance of FLAG-I $\kappa \mathrm{B} \alpha$ Mut to TNF $\alpha$ induced proteolysis. Western blot of cytoplasmic extracts prepared from cells cultured in the presence or absence of Dox and stimulated for the indicated times with TNF $\alpha$. Western blot was probed with antibody to $\mathrm{I} \kappa \mathrm{B} \alpha$, detecting the FLAG-I $\kappa \mathrm{B} \alpha$ Mut (top band) and endogenous $\mathrm{I} \kappa \mathrm{B} \alpha$ (bottom band). FLAG-I $\kappa \mathrm{B} \alpha$ Mut inhibits the expression of endogenous $\mathrm{I} \kappa \mathrm{B} \alpha$ and is not proteolyzed by TNF treatment. Control for protein loading was performed by reprobing the membrane for $\beta$-actin (bottom). [Data adapted from Tian B, Zhang Y, Luxon BA, Garofalo RP, Casola A, Sinha M, Brasier AR 2002 Identification of NF- $\kappa$ B dependent gene networks in respiratory syncytial virus-infected cells. J Virol 76:6800-6814.]

the FLAG-I $\kappa \mathrm{B} \alpha$ Mut protein is not. Finally, RNAse protection assays demonstrated that sufficient NF- $\kappa \mathrm{B}$ inhibition was achieved to interfere with expression of known NF- $\kappa$ B-dependent target genes (Figure 5). In this experiment, cells cultured in the absence or presence of Dox were infected with RSV and steady-state levels of RANTES, IP-10, and IL-8 were measured simultaneously 


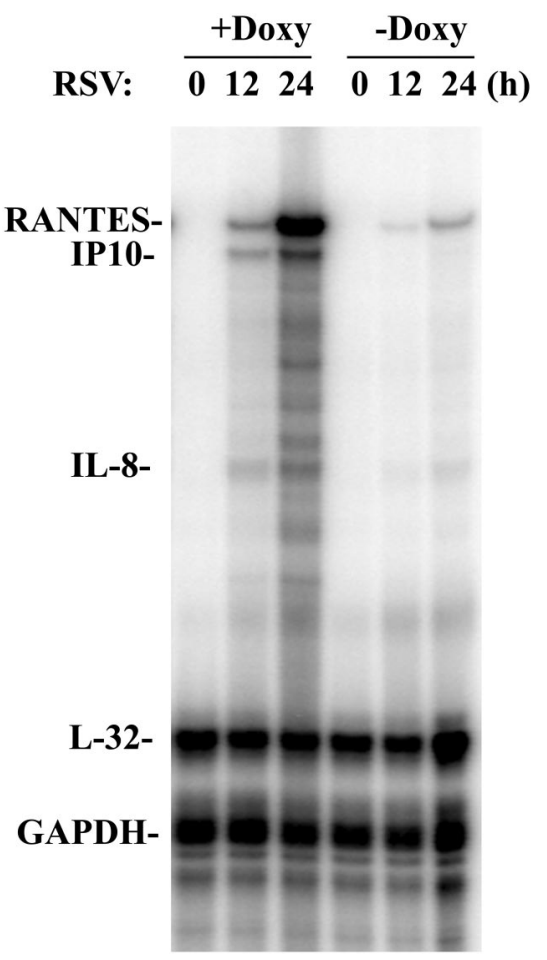

FIG. 5. Effect of FLAG-I $\kappa \mathrm{B} \alpha$ Mut expression on NF- $\kappa \mathrm{B}-$ dependent transcription. Cells were cultured in the absence or presence of Doxy for 7 days and infected with purified respiratory syncytial virus (RSV) (multiplicity of infection (MOI 1)) for indicated times (in hours) prior to harvest of total cellular RNA. mRNA abundance was determined in each sample by multiprobe ribonuclease protection assay (RPA). Shown is an autoradiographic exposure after denaturing gel electrophoresis. Location of protected fragments for RANTES (regulated upon activation, normally T-cell expressed and presumably secreted), IP-10, interleukin (IL)-8, and the two housekeeping genes, L32 and glyceraldehye-3-phosphate dehydrogenase (GAPDH), is indicated at left. FLAG-I $\kappa \mathrm{B} \alpha$ Mut inhibits viral-inducible RANTES, IP-10, and IL-8 expression. [Data adapted from Tian B, Zhang Y, Luxon BA, Garofalo RP, Casola A, Sinha M, Brasier AR 2002 Identification of NF- $\kappa$ B dependent gene networks in respiratory syncytial virus-infected cells. J Virol 76:6800-6814.]

by ribonuclease protection assay (RPA). The strong viral-inducible and timedependent induction of RANTES, IP-10, and IL-8 was inhibited significantly in cells cultured in the absence of Dox. Control experiments, published earlier, indicated that similar levels of viral transcription was occurring in both cells (Tian et al., 2002). Together, these data indicated that we could achieve a robust and highly reproducible inhibition of NF- $\kappa \mathrm{B}$-dependent translocation and nuclear actions in response to a variety of stimuli. 
With this information, high-density oligonucleotide arrays were used to assay for profiles of gene expression in response to RSV infection in the presence of FLAG-I $\kappa \mathrm{B} \alpha$ Mut vs. those induced in its absence.

\section{Identification of NF- $\kappa$ B-dependent Gene Network in Viral Infection}

We were interested in identifying NF- $\kappa \mathrm{B}$-dependent genes in response to a complex biological stimulus, mucosal viral infection with RSV. RSV, a negativesense RNA virus of the paramyxoviridae family, is the leading cause of epidemic bronchiolitis and pneumonia in children (Ruuskanen and Ogra, 1993). Lacking an effective vaccine, infection with this ubiquitous virus causes $40-60 \%$ of the bronchiolitis and 15-25\% of the pneumonia cases in hospitalized children (Shay et al., 1999), accounting for $\approx 100,000$ hospitalizations and $\approx 500$ deaths annually in the United States (Shay et al., 2001). RSV productively replicates at high levels in a variety of airway epithelial cells, where it potently alters host gene expression. Our work using high-density oligonucleotide arrays has shown that at least 16 different $\mathrm{C}, \mathrm{CC}, \mathrm{CXC}$, and $\mathrm{CX}_{3} \mathrm{C}$ chemokines are expressed by $\mathrm{RSV}$-infected respiratory epithelial cells in three general expression profiles (Garofalo et al., 1996; Casola et al., 2000b; Zhang et al., 2001). Of these, several are known to be induced through an $\mathrm{NF}-\kappa \mathrm{B}$-dependent mechanism involving $\mathrm{I} \kappa \mathrm{B} \alpha$ proteolysis (Garofalo et al., 1996; Jamaluddin et al., 1998). Importantly, inhibition of NF- $\kappa$ B prevents RSV-induced airway inflammation in experimental models of infection (Haeberle et al., 2002). Together, we interpret these data to indicate that the actions of $\mathrm{NF}-\kappa \mathrm{B}$ are to induce the expression of genes important in airway inflammation.

To identify these potential pathology-inducing genes, we subjected RNA for high-density oligonucleotide array analysis extracted from control or infected cells ( \pm Dox treatment). For comparison of the fluorescent intensity (average difference) values among multiple experiments, we normalized the data relative to the $2 \%$ trimmed mean, a global hybridization metric to correct for changes in hybridization efficiency (Zhang et al., 2001; Tian et al., 2002). The normalized average difference values were then subjected to a two-way analysis of variance (ANOVA with replications) to determine which genes were significantly influenced by either the RSV or Dox treatment. We found that RSV infection significantly changed the abundance of 1359 mRNAs, while FLAG-I $\kappa \mathrm{B} \alpha$ Mut expression influenced only 380 gene-expression profiles. Comparison of the two groups found only 144 genes common to the two treatments. The proteins encoded by the genetic group sensitive to RSV + FLAG-I $\kappa \mathrm{B} \alpha$ Mut expression were classified by their putative biological pathways (Table I). Notably, members of a wide variety of biological pathways were identified. Numerically, the largest groups included membrane proteins, metabolic enzymes, signaling molecules 
TABLE I

Classification of NF-кB-dependent Gene Network

\begin{tabular}{|c|c|}
\hline Common name & GenBankID \\
\hline \multicolumn{2}{|l|}{ Apoptosis } \\
\hline IAP-1 & $\mathrm{U} 45878$ \\
\hline THBS2 & L12350 \\
\hline \multicolumn{2}{|l|}{ Cell cycle } \\
\hline $\mathrm{Rb}$ & HG4036-HT4306 \\
\hline $\mathrm{TSC} 1$ & AF013168 \\
\hline CETN1 & U03270 \\
\hline ZNF211 & U38904 \\
\hline \multicolumn{2}{|l|}{ Chemokines/cytokines } \\
\hline IL-8 & M28130 \\
\hline IFN-gamma & J00219 \\
\hline MGSA/Gro-alpha & X54489 \\
\hline RANTES & M21121 \\
\hline SCYA22 & AC004382 \\
\hline \multicolumn{2}{|l|}{ Cytoskeletal } \\
\hline TUBG1 & M61764 \\
\hline COL16A1 & M92642 \\
\hline COL11A1 & J04177 \\
\hline Merlin & L11353 \\
\hline BENE & U17077 \\
\hline $\mathrm{NuP} 214$ & X64228 \\
\hline STXBP1 & AF004563 \\
\hline \multicolumn{2}{|l|}{ Membrane protein } \\
\hline PRGP1 & AF009242 \\
\hline Type II mem protein & AB015633 \\
\hline QA79 membrane protein & AJ007395 \\
\hline EPB41L1 & AB002336 \\
\hline
\end{tabular}




\begin{tabular}{|c|c|}
\hline Common name & GenBankID \\
\hline N33 & $\mathrm{U} 42360$ \\
\hline SNAP25 & D21267 \\
\hline EBNA1BP2 & U86602 \\
\hline \multicolumn{2}{|l|}{ DNA maintenance } \\
\hline DNAse gamma & U75744 \\
\hline UBE2V1 & U49278 \\
\hline \multicolumn{2}{|l|}{ Growth factors } \\
\hline IGF-1b & HG2309-HT2405 \\
\hline \multicolumn{2}{|c|}{ Histocompatability and cell surface } \\
\hline GAGE-2 & U19143 \\
\hline HLA-G & AL022723 \\
\hline MIC2 & M16279 \\
\hline CD59 & M84349 \\
\hline \multicolumn{2}{|c|}{ Ion channels and transporters } \\
\hline SCNN1B & X87159 \\
\hline \multicolumn{2}{|l|}{ Metabolism } \\
\hline GST & M16594 \\
\hline PSMD13 & AB009398 \\
\hline Chol 25 OH lase & AF059214 \\
\hline ATPase homolog & AF020736 \\
\hline TYMS & X67098 \\
\hline CYP11B1 & X55764 \\
\hline TIMP-2 & U44385 \\
\hline SL15 & AF038961 \\
\hline GALT & M60091 \\
\hline PSMB5 & D29011 \\
\hline 5' ALA synthase & Y00451 \\
\hline
\end{tabular}


TABLE I

(continued)

\begin{tabular}{|c|c|}
\hline Common name & GenBankID \\
\hline Enolase 3 & X56832 \\
\hline E2Ub-conj & AA883502 \\
\hline Selenium donor & U34044 \\
\hline TCP20 & D78333 \\
\hline ALDH3A2 & U46689 \\
\hline ACAA1 & X14813 \\
\hline CANPX & AJ000388 \\
\hline UBE4B & AF043117 \\
\hline Beta glucuronidase & X75940 \\
\hline GGT & J04131 \\
\hline PIGCP1 & AB000359 \\
\hline \multicolumn{2}{|l|}{ Oncogenes } \\
\hline PEP1 & L16464 \\
\hline PLCB4 & L41349 \\
\hline \multicolumn{2}{|l|}{ Receptors } \\
\hline FGFR4 & L03840 \\
\hline CD160 & AF060981 \\
\hline TLR-3 & U88879 \\
\hline TSHR & S49816 \\
\hline Frizzled-1 & AB017363 \\
\hline Frizzled & L37882 \\
\hline IL15RA & AF035279 \\
\hline Cadherin & AL031588 \\
\hline \multicolumn{2}{|l|}{ RNA metabolism } \\
\hline RAE1 & U84720 \\
\hline RNAP A0 & $\mathrm{U} 23803$ \\
\hline RNMT & AF009426 \\
\hline
\end{tabular}


TABLE I

(continued)

\begin{tabular}{|c|c|}
\hline Common name & GenBankID \\
\hline \multicolumn{2}{|c|}{ Secreted proteins and peptides } \\
\hline IGF-BP6 & M62402 \\
\hline hGH & J03071 \\
\hline Comp. B & L15702 \\
\hline Factor VIII & M14113 \\
\hline \multicolumn{2}{|l|}{ Signaling molecules } \\
\hline EphB4 & U07695 \\
\hline PTPRR & D64053 \\
\hline MAPKK6 & U39064 \\
\hline AKAP95 & Y11997 \\
\hline RAGA & U41654 \\
\hline Ndr protein kinase & Z35102 \\
\hline PTPRB & X54131 \\
\hline Rap2 & X12534 \\
\hline PTPN1 & M33684 \\
\hline RAB4 & M28211 \\
\hline Rar & U05227 \\
\hline Dmx-like 1 & AJ005821 \\
\hline PRKWNK1 & AB002342 \\
\hline Synaptojanin 2B & AF039945 \\
\hline $\mathrm{CDC} 2 \mathrm{~L} 2$ & AL031282 \\
\hline GCN1 & D50919 \\
\hline \multicolumn{2}{|l|}{ Transcription factors } \\
\hline PLA-1 & AJ012214 \\
\hline STAT-1 & M97936 \\
\hline IRF-7B & U53831 \\
\hline MITF & AB006909 \\
\hline
\end{tabular}


TABLE I

(continued)

\begin{tabular}{lr}
\hline Common name & \multicolumn{1}{c}{ GenBankID } \\
\hline IkB epsilon & $\mathrm{U} 91616$ \\
IRF-9 & $\mathrm{M} 87503$ \\
NF- $\kappa$ B & $\mathrm{X} 61498$ \\
NF- $\kappa$ B2 & $\mathrm{S} 76638$ \\
NR4A2 & $\mathrm{S} 77154$ \\
Nuclear Factor 1 & HG4167-HT4437 \\
Cdx2 & $\mathrm{U} 51096$ \\
TCEAL1 & M99701 \\
\hline
\end{tabular}

[The proteins encoded by the 144-member genetic network under control by respiratory syncytial virus (RSV) and FLAG-I $\kappa \mathrm{B} \alpha$ Mut expression were classified by putative biochemical activity. For each group, the common name is listed with the GenBank accession number. GenBank ID numbers of probe sets that could not be classified are not included. They are U51698, AF070549, AI538199, AL041663, AI687419, AL121073, W27666, AB029012, Y18504, AL096750, AI925946, AF035300, AB002308, AB014559, AB007975, AF035292, AB018324, AB023201, D31764, M92357, AB023215, AA846749, AB002375, AL050002, AB002304, AB002350, AI936826, AI741833, W27517, AB014528, D50911, AC005053, AI793265, AI921843, AA477898, AB020628, $\mathrm{AB} 014608, \mathrm{AB} 018259$, and L22342.]

(i.e., kinases, phosphatases), transcription factors, and those of unknown function.

To better visualize the gene-expression changes in the 144-member group regulated by both RSV and FLAG-I $\kappa \mathrm{B} \alpha$ Mut expression, hierarchical clustering was performed. In this technique, each gene-expression profile is grouped with its nearest neighbor and the mathematical proximity of this gene-expression profile is indicated by the height of a common line that connects the two nodes. A representative analysis is shown in Figure 6, where each treatment condition represents the average of the normalized average difference values from three independent experiments. From visual inspection of the dendogram, the geneexpression patterns are divided into two large clusters. The top cluster contains a group of genes whose constitutive (unstimulated) expression is high and falls with RSV infection. In this group, inhibition of NF- $\kappa$ B reduces the viral-induced inhibition of their expression. The bottom cluster contains a group of genes whose constitutive expression is low and is strongly increased by RSV infection. In this group, inhibition of NF- $\kappa \mathrm{B}$ blocks the viral-induced activation of their expression. 


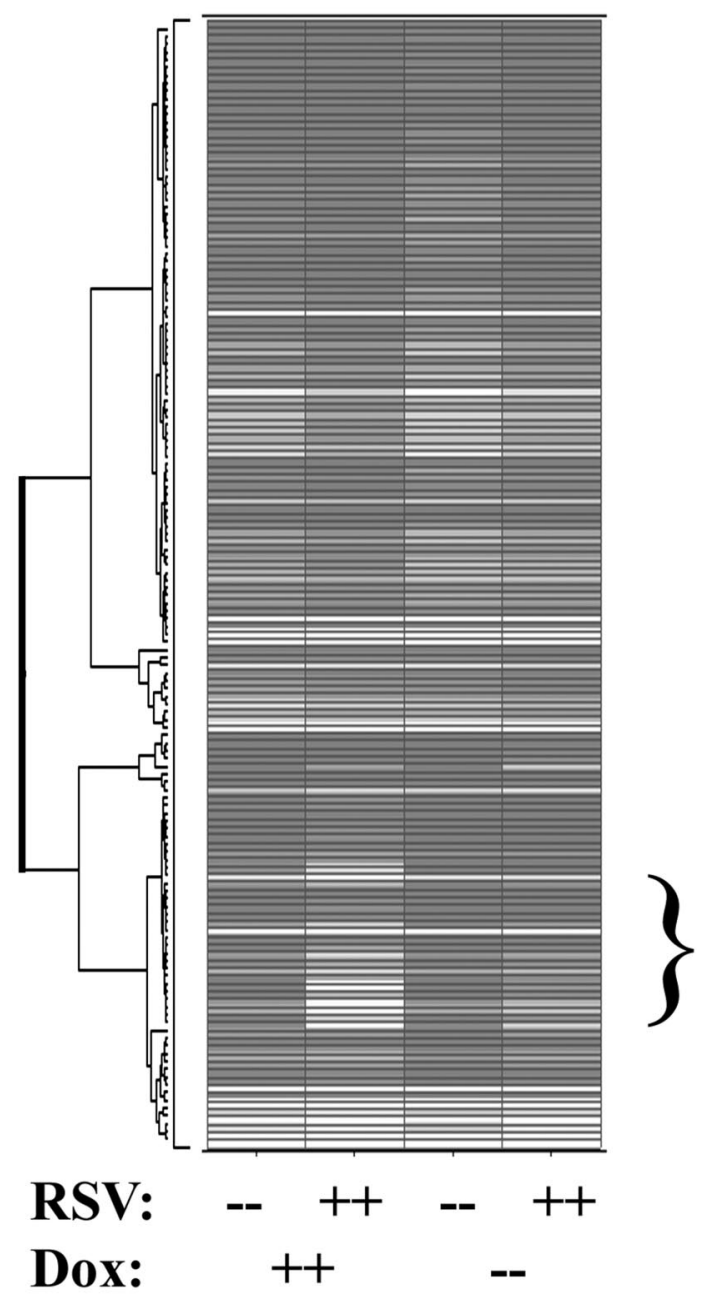

FIG. 6. NF- $\kappa$ B-dependent gene networks identified by high-density microarrays. Clustering and heat map analysis of the RSV and FLAG-I $\kappa \mathrm{B} \alpha$ Mut-regulated dataset. Cells cultured in the presence or absence of Dox were exposed to RSV for 12 hours prior to RNA extraction and analysis by high-density microarrays. Agglomerative hierarchical clustering was performed on average fluorescence intensity values from three independent experiments using the unweighted pair group method with arithmetic mean (UPGMA) technique. A heat map for each gene for the three independent experimental datapoints is shown at right. The gradient used is dark gray (minimum value of 5 scaled fluorescence intensity units), light grey (middle value of 5000 scaled units), and white (maximum value of 10,000 scaled units). The bracket at right indicates the subset of highly inducible NF- $\kappa \mathrm{B}$ genes shown in Table I and analyzed in Figure 8. [Data adapted from Tian B, Zhang Y, Luxon BA, Garofalo RP, Carola A, Sinha M, Brasier AR 2002 Identification of NF- $\kappa$ B dependent gene networks in respiratory syncytial virus-infected cells. J Virol 76:6800-6814.] 
The genes with high constitutive activity whose expression fell with RSV treatment were classified into biochemical pathways to determine whether a single process was being influenced by NF- $\kappa$ B action. Disappointingly, approximately half of the genes were unknown and, of those that could be identified, no signal pathway emerged. For example, we found secreted peptides (growth hormone, Genbank Accession No. J03071), intracellular signaling proteins (tyrosine phosphatase, X54131; serine/threonine kinase, AB018324; RAB4, M28211), nucleic acid binding proteins (RNPA0, U23803), metabolic enzymes (enolase, X56832; selenium donor, U34044), transcription factors (micro-opthalmia-associated transcription factor, AB006909), extracellular structural proteins (type XI collagen, J04177; $\alpha 1$-type XVI collagen, M92642), and others (Tian et al., 2002). Control experiments also indicated that expression of other genes in this list was influenced by Dox treatment. The mechanisms for NF- $\kappa \mathrm{B}$-dependent gene downregulation will require independent analysis and further study.

A similar analysis was conducted for the genes whose constitutive activity was low and whose induction by RSV was blocked by FLAG-I $\kappa \mathrm{B} \alpha$ Mut expression. We identified secreted complement factors (complement $\mathrm{B}$ ), transcription factors (the proteolytically processed NF- $\kappa \mathrm{B}$ member, NF- $\kappa \mathrm{B} 2$; the signal transducer and activator of transcription, STAT-1; the interferon regulatory factors, IRF-9 and IRF-7), metabolic enzymes (5'-aminolevulinate synthase); growth factor binding proteins (insulin-like growth factor binding protein 6), kinases in translational control (human GCN1), cytokines (RANTES, IL-8), and others (B94). The group indicated by the parentheses in Figure 6 is also tabulated (Table II). Again, no single biological pathway is easily seen, although identifying some of the previously known NF- $\kappa$ B-dependent genes (e.g., IL-8, RANTES) was an important validation of our system and analysis (Figure 5). Together, these data suggest that NF- $\kappa$ B plays a multifaceted role in control of constitutive gene expression, involvement in RSV-mediated downregulation of genes, as well as in mediating upregulation of a network of RSV-inducible genes.

\section{Insights into Biological Roles of NF- $\mathrm{BB}$ Through the Functions of Its Downstream Genes}

RSV is a negative-sense RNA virus that is replicated in the cytoplasm through its own RNA-dependent RNA polymerase. In RSV infection, therefore, $\mathrm{NF}-\kappa \mathrm{B}$ has no role in viral transcription and its purpose is to activate expression of the host's innate immune and inflammatory responses. A number of highly inducible genes encoding cytokine, chemokine, acute-phase reactant, and adhesion molecules contain NF- $\kappa \mathrm{B}$-binding sites in their proximal promoters and, in a certain number of cases, are induced by RSV (Li and Brasier, 1996; Brasier et al., 1998; Thomas et al., 1998a; Casola et al., 2001; reviewed in Zhang and Ghosh, 2001). However, whether NF- $\kappa \mathrm{B}$ is truly a master regulator of gene 
TABLE II

$N F-\kappa B$ Binding Site Prediction for Highly RSV-inducible Genes

\begin{tabular}{|c|c|c|c|c|}
\hline \multirow[b]{2}{*}{ Name } & \multicolumn{2}{|c|}{ Similarity scores } & \multirow[b]{2}{*}{ Sequence } & \multirow{2}{*}{$\begin{array}{l}\text { Experimental } \\
\text { verification }\end{array}$} \\
\hline & Core & Matrix & & \\
\hline MGSA/Gro-alpha & 1 & 0.964 & ccGGGAAtttccet & $\mathrm{Y}$ \\
\hline IL-8 & 0.863 & 0.92 & cgTGGAAtttcctc & $\mathrm{Y}$ \\
\hline RANTES & 0.955 & 0.974 & ttggaaaCTCCCct & $\mathrm{Y}$ \\
\hline IRF-9 & & & & $\mathrm{NF}$ \\
\hline IRF-7B & 0.955 & 0.941 & ccggaaaCTCCCgc & $\mathrm{Y}$ \\
\hline STAT1 & & & & $\mathrm{NF}$ \\
\hline Chol $25 \mathrm{OH}$ lase & & & & $\mathrm{NF}$ \\
\hline CYB11B1 & & & & $\mathrm{NF}$ \\
\hline \multirow[t]{2}{*}{ IAP-1 } & & & 5'-GGAAATCCCC-3' & $\mathrm{Y}$ \\
\hline & & & 5'-TGGAGTTCCC-3' & $\mathrm{Y}$ \\
\hline \multirow[t]{3}{*}{ NF- $\kappa$ B2 (promoter 1) } & 1 & 0.991 & GGGGAtcccc & $\mathrm{Y}$ \\
\hline & 0.955 & 0.906 & gcggaagCTCCCgg & $\mathrm{NF}$ \\
\hline & 1 & 0.967 & atgggaaTTCCCcc & $\mathrm{NF}$ \\
\hline IkB epsilon & & & & $\mathrm{NF}$ \\
\hline E2Ub-conj & & & & $\mathrm{NF}$ \\
\hline GCN1 & & & & $\mathrm{NF}$ \\
\hline Comp B & 1 & 0.943 & atggaatTTCCCag & $\mathrm{NF}$ \\
\hline IGFBP6 & & & & $\mathrm{NF}$ \\
\hline Type II Mem protein & & & & $\mathrm{NF}$ \\
\hline Nuclear phosphoprotein & & & & $\mathrm{NF}$ \\
\hline PTPN1 & & & & $\mathrm{NF}$ \\
\hline 5'ALA synthase & 1 & 0.911 & cgGGGAAtccccgg & $\mathrm{NF}$ \\
\hline IL-15R alpha & 1 & 0.935 & gtgggatTTCCCca & $\mathrm{Y}$ \\
\hline GAGE-2 & & & & $\mathrm{NF}$ \\
\hline Cadherin-like 22 & & & & $\mathrm{NF}$ \\
\hline B94 & & & & $\mathrm{NF}$ \\
\hline
\end{tabular}

[Subgroup of highly inducible genes taken from hierarchical clustering (marked by parentheses, see Figure 6) were classified by primary biological function. Shown are the core and matrix similarities from the TRANSFAC analysis for NF- $\kappa$ B binding sites. $\mathrm{Y}=$ experimental verification of the NF- $\kappa$ B binding site was found; NF $=$ not found.] 
expression in mucosal viral infection and which genes it controls have not been subjected to direct experimental investigation. A surprising finding from our study is the relatively small number of genes that were sensitive to FLAG-I $\kappa \mathrm{B} \alpha$ Mut expression. Of the 1359 RSV-inducible genes, only about $10 \%$ were shown to be NF- $\kappa \mathrm{B}$ dependent. It is important to emphasize that our analysis is based on whether a given gene is induced by virus for us to identify it as an NF- $\kappa \mathrm{B}$ target. In this regard, a study using a similar approach to identify NF- $\kappa \mathrm{B}$ dependent genes in rat pancreatic $\beta$ cells identified 66 genes under $\mathrm{NF}-\kappa \mathrm{B}$ control (Cardozo et al., 2001). The NF- $\kappa \mathrm{B}$-dependent targets that this study identified in pancreatic $\beta$ cells were markedly different from those found in our study. In $\beta$ cells, the most highly upregulated genes are inducible peptide $10 \mathrm{kDa}$ (IP-10), IL-15, cluster of differentiation-40 (CD-40), and major histocompatibility complex (MHC)-II-associated invariant chain. Like our findings, a number of genes were downregulated in an NF- $\kappa \mathrm{B}$-dependent manner, including the Pdx-1 transcription factor, a $\beta$-cell differentiation factor that controls the expression of glucose transporters (Cardozo et al., 2001). These surprising differences between our studies indicate that the "NF- $\kappa \mathrm{B}$ network" is under cell type-specific control. Also, species-specific effects come into play as, for example, rats do not have an IL-8 gene.

In human epithelial-derived cells, our studies show that NF- $\kappa \mathrm{B}$ is important in RSV-inducible gene expression for a number of genes with apparently diverse functions, including chemokines, transcription factors (interferon regulatory factor (IRF)/signal transducers and activators of transcription (STATs) and $\mathrm{NF}-\kappa \mathrm{B} / \mathrm{I} \kappa \mathrm{B}$ members), proteins controlling translation/proteolysis, secreted proteins, cytoskeletal elements, and signaling proteins in those whose function is known (Table I). Clearly, these observations will have to be extended for other $\mathrm{NF}-\kappa \mathrm{B}$-activating stimuli and into other cell types. Our observations further suggest that not only does $\mathrm{NF}-\kappa \mathrm{B}$ play a role in viral-dependent gene activation, it also plays a role in constitutive and viral-dependent inhibition of distinct genetic elements. In the following paragraphs, we comment on some of the biological insights that this study suggested (see Figure 7 for a schematic overview).

\section{A. CONTROL OF NEUTROPHILIC AND EOSINOPHILIC CHEMOKINE EXPRESSION}

Cellular recruitment into the virally infected lung is a multistep process involving adherence of circulating leukocytes to an activated endothelial surface, followed by their diapedesis into the inflamed tissue and migration toward chemical gradients of chemoattractant peptides or antigens (reviewed in Springer, 1994). Recent attention has focused on the important role of chemokines in mediating leukocyte chemotaxis into the airways. Chemokines are a 


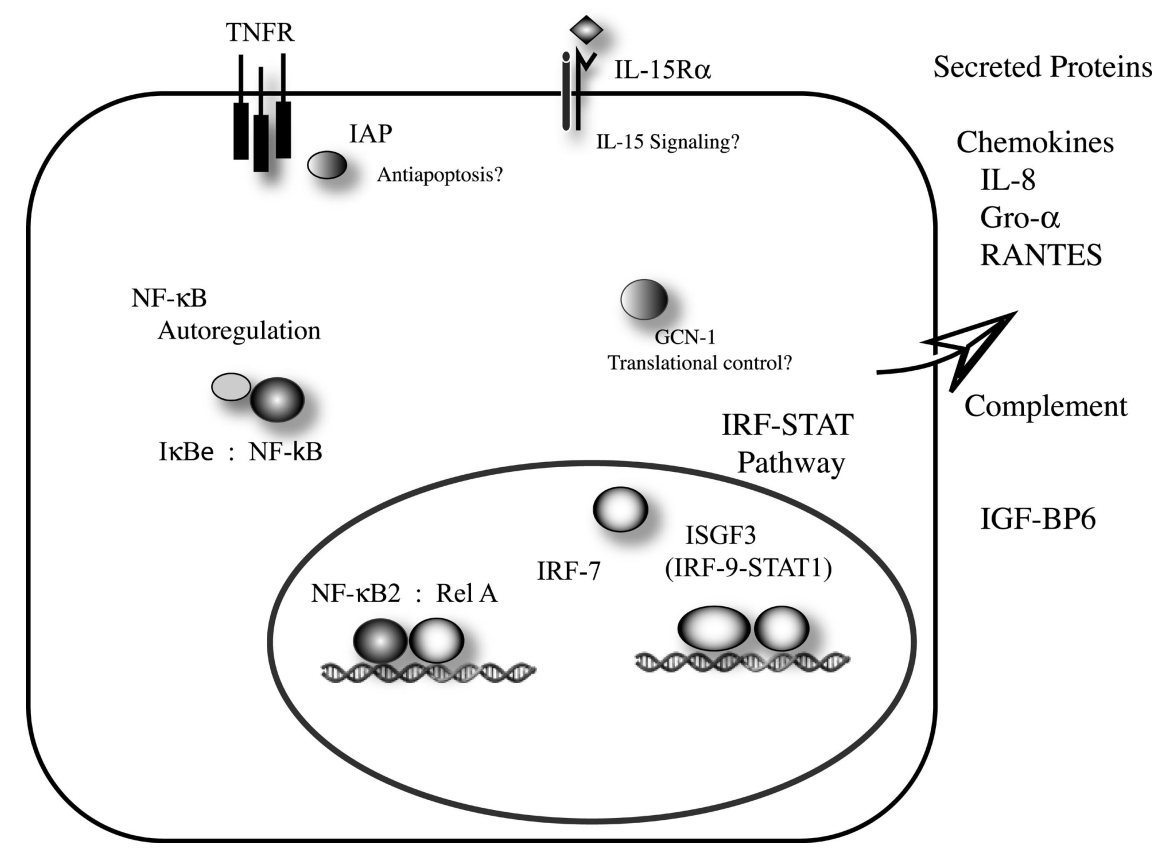

FIG. 7. Putative biological functions for NF- $\kappa$ B-dependent genes. Abbreviations: GRO, growth-regulated oncogene; IAP, inhibitor of apoptosis; IGFBP, insulin-like growth factor binding protein; IRF, interferon regulatory factor; ISGF, interferon-stimulated gene factor; TNFR, tumor necrosis factor receptor. [See text for discussion.]

superfamily of proteins divided into four distinct groups - C, CC, CXC, and $\mathrm{CX}_{3} \mathrm{C}$ - based on the number and spacing of highly conserved $\mathrm{NH}_{2}$-terminal cystine residues (reviewed in Oppenheim et al., 1991; Baggiolini et al., 1997). This grouping has functional significance because the spacing of the $\mathrm{NH}_{2}-$ terminal cystine residues influences the type of cell-surface leukocyte receptors that they bind to produce leukocyte activation and chemotaxis. Although a number of cell types can inducibly secrete chemokines, the airway epithelium is thought to play a central role in initiating pulmonary inflammation by RSV because the epithelium is the first target for RSV replication and the mucosa is the only tissue that allows productive viral replication. Our recent studies using high-density oligonucleotide arrays have shown that at least 16 different $\mathrm{C}, \mathrm{CC}$, $\mathrm{CXC}$, and $\mathrm{CX}_{3} \mathrm{C}$ chemokines are expressed by RSV-infected respiratory epithelial cells in three general expression profiles (Zhang et al., 2001). The molecular mechanisms controlling expression of CXC- and CC-type chemokines in RSVinfected airway epithelial cells have been investigated extensively (Garofalo et al., 1996; Brasier et al., 1998; Thomas et al., 1998a; Casola et al., 2000b). Our 
studies here show that the NF- $\kappa \mathrm{B}$-dependent chemokine group contains the $\mathrm{CXC}$ chemokines GRO- $\alpha$ and IL- 8 and the CC chemokine RANTES. The CXC chemokine class is potent chemotactic cytokines for activated neutrophils and is functionally subdivided into two groups, based on the presence or absence of a signature ELR (Glu-Leu-Arg) motif upstream of the canonical CXC motif. The ELR-containing group of CXC chemokines includes IL-8, GRO- $\alpha$, and ENA78. These cytokines primarily activate the bacteriocidal activity and chemotaxis of neutrophils, an abundant cell type found in the bronchoalveolar lavage of intubated, RSV-infected children (Everard et al., 1994). The ELR CXC chemokines can activate other target cells. For example, IL-8 activates T cells and eosinophils (Matsushima and Oppenheim, 1989; Murphy, 1994), while GRO- $\alpha / \beta / \gamma$ activate basophils (Geiser et al., 1993). This may account for some of the spectrum of cellular infiltration in RSV-infected lungs and presence of cell-specific degranulation products in nasopharyngeal secretions in patients with naturally acquired RSV infection (Garofalo et al., 1992).

The CC chemokine RANTES, originally described as a T cell-derived chemokine, is now known to be highly expressed in stimulated airway epithelial cells, where it may serve to recruit $\mathrm{T}$ lymphocytes, monocytes, basophils, and eosinophils into the virally infected lung (Alam et al., 1994). RANTES has been shown to be highly NF- $\kappa \mathrm{B}$ dependent by our studies and those of others (Thomas et al., 1998a; Casola et al., 2000b). Of relevance, RANTES has been shown to be present in nasal washes of children infected with RSV, where its levels and those of its cellular target, eosinophilic degranulation products, correlate with disease severity (Garofalo et al., 1994; Teran et al., 1996). Our studies suggest that NF- $\kappa \mathrm{B}$ controls the expression of chemokines important in neutrophilic and eosinophilic recruitment into the airways.

\section{B. CONTROL OF IFN SIGNALING PATHWAY}

We were surprised that the NF- $\kappa \mathrm{B}$-dependent gene list contained important members of two transcription factor families, STAT-1 and IRF-9 and IRF-7B. STATs are cytosolic proteins contained in high molecular mass complexes ("statosomes") (Ndubuisi et al., 1999) activated by tyrosine phosphorylation mediated by the interferon and growth factor receptor-associated kinases, Jak and Tyk (reviewed in Schindler and Darnell, 1995). Activated STATs form homo- or heterodimers through intermolecular $\mathrm{SH}_{2}$ phosphotyrosine interactions and subsequently are translocated into the nucleus in distinct binding complexes dictated by the nature of the stimulus and target promoters (Taniguchi et al., 2001). The IRFs are a family of nine constitutive and inducible helix-turn-helix transcription factors important in innate defense through their ability to mediate viralinducible transcription of cytokine and chemokine genes (reviewed in Taniguchi et al., 2001). IRF-9 is a DNA-binding component of the ISGF3 complex induced 
by $\alpha$-IFN. ISGF3 contains STATs -1 and $2-$ as well as IRF-9. The observation that two important components of ISGF3 are controlled by NF- $\kappa$ B highlights an interdependent relationship between these transcription factor families. Perhaps not surprisingly, others have shown the IRF-7 promoter contains an NF- $\kappa \mathrm{B}$-binding site, mediating its response to cytokine stimulation (Lu et al., 2002). STAT1, to our knowledge, is not known to be NF- $\kappa \mathrm{B}$ dependent. However, our findings that the STAT/IRF family members are downstream of NF- $\kappa \mathrm{B}$ in viral infection suggests an important mechanism for how NF- $\kappa \mathrm{B}$ plays an important role in innate immunity by facilitating signaling through the interferon pathway.

\section{NF- $\kappa$ B AUTOREGULATION}

Autoregulation recently has been recognized to be an important controller of network stability. Studies of synthetic gene circuits have shown, for example, that negative feedback reduces the variability in target gene expression by limiting the range over which the concentrations of the signaling molecules operate (Becskei and Serrano, 2000). Remarkably, in our analysis, members of the NF- $\kappa \mathrm{B}$ activation pathway themselves are NF- $\kappa \mathrm{B}$ dependent. Of the members of the NF- $\kappa$ B pathway identified in this study, the inhibitor of apoptosis (IAP-1)/cIAP-2 is an upstream regulator of caspase activation that associates with the tumor necrosis factor receptor 1 (TNFR1) and death domain-containing receptors. Inducible expression of IAP-1 may be one mechanism through which NF- $\kappa$ B exerts its antiapoptotic effect. In support of our analysis, IAP-1 previously has been shown to be transcriptionally regulated by NF- $\kappa \mathrm{B}$ (Hong et al., 2000). The DNA-binding subunit, NF- $\kappa \mathrm{B} 2$, is an NF- $\kappa \mathrm{B} 1$ homolog encoded by a large, 105-kDa precursor that must be processed into its 50-kDa binding form. Like IAP-1, NF- $\kappa$ B2 is known to be regulated by NF- $\kappa \mathrm{B}$ (Liptay et al., 1994). Although both NF- $\kappa \mathrm{B} 1$ and NF- $\kappa \mathrm{B} 2$ are inducible genes, in RSV-infected epithelial cells, expression of NF- $\kappa \mathrm{B} 2$ is predominately NF- $\kappa \mathrm{B}$ dependent. Unlike NF- $\kappa \mathrm{B} 1, \mathrm{NF}-\kappa \mathrm{B} 2$ is a potent transcriptional activator in heterodimeric form with Rel A (Schmid et al., 1991). These observations suggest that epithelial stimulation by NF- $\kappa$ B-activating agents changes the distribution of Rel A heterodimers, allowing the cell to respond differently to subsequent signals. Another well-established NF- $\kappa \mathrm{B}$-dependent target is that of the I $\kappa \mathrm{B}$ inhibitors themselves (Han et al., 1999a; Brasier et al., 2001). Activation of the $\mathrm{I} \kappa \mathrm{B}$ members is an autoregulatory feedback loop where NF- $\kappa$ B induces the synthesis of its own inhibitor to terminate its action. Previously, we showed that the NF- $\kappa \mathrm{B}-\mathrm{I} \kappa \mathrm{B} \alpha$ autoregulatory loop was impaired in RSV-infected cells. This finding explains why $\mathrm{I} \kappa \mathrm{B} \alpha$ was not identified in the present analysis (Jamaluddin et al., 1998). $\mathrm{I} \kappa \mathrm{B} \epsilon$, in contrast to $\mathrm{I} \kappa \mathrm{B} \alpha$, is strongly upregulated by RSV infection and suggests stimulus-specific differences in the NF- $\kappa \mathrm{B}$-dependent expression 
control of individual $\mathrm{I} \kappa \mathrm{B}$ subunits. Notwithstanding, the induction of $\mathrm{I} \kappa \mathrm{B} \epsilon$ may compensate for a relative deficiency in $\mathrm{I} \kappa \mathrm{B} \alpha$. The existence of multiple, independent NF- $\kappa \mathrm{B}-\mathrm{I} \kappa \mathrm{B}$ and NF- $\kappa \mathrm{B}-\mathrm{BCL}-3$ inhibitory loops suggests that unregulated NF- $\kappa$ B activation is highly deleterious (Jamaluddin et al., 1998; Han et al., 1999a; Brasier et al., 2001).

\section{OTHER FUNCTIONS}

Our study has identified a number of other highly NF- $\kappa \mathrm{B}$-dependent genes that do not easily fit into a single biological pathway (Table I). The functional consequences of enhanced expression of $5^{\prime}$ aminolevulinate synthase, a ratelimiting enzyme in heme biosynthesis, is unknown to us but suggests a role for $\mathrm{NF}-\kappa \mathrm{B}$ in viral-regulated heme metabolism in nonerythroid cells. Conversely, the NF- $\kappa$ B dependence of the E2-ubiquitin-conjugating enzyme suggests that NF- $\kappa$ B activation may have an important role in determining cellular capacity to break down proteins regulated through the ubiquitin-proteasome pathway, a process important in cell-surface presentation of viral antigens in the context of MHC class I molecules. We were surprised to identify a human homolog of the Saccharomyces cerevisiae GCN1 gene, a protein controlling translational efficiency through modifying upstream activation of the eIF2 protein kinase (Marton et al., 1997). Gene expression/regulation studies of hGCN1 in the setting of viral infection have not been reported to our knowledge, although viral infections are known to profoundly influence translational regulation. Complement factor B, a hepatic acute-phase response factor important in the alternative complement pathway, is well known to be NF- $\kappa$ B inducible (Nonaka and Huang, 1990). However, viral induction of the alternative complement pathway and its role in response to infection have not been investigated. The induction of insulin-like growth factor binding protein 6 (IGF-BP6) suggests that viral-infected cells exert paracrine control on the mitogenic actions of IGF-II (Gabbitas and Canalis, 1997). Perhaps IGF-BP6 expression is beneficial to prevent local cellular proliferation in the presence of an infecting viral agent. Upregulation of the $\alpha$ subunit of the IL-15 receptor may suggest that viral-infected cells have distinct signaling phenotypes to cytokines as a result of NF- $\kappa$ B action. Finally, B94 was identified as a highly cytokine- and lipopolysaccharide (LPS)-inducible transcript (Sarma et al., 1992) that may play a role in angiogenesis, spermatogenesis, or myelogenesis. Our data suggest that B94 is also a viral-inducible transcript in epithelial cells through an NF- $\kappa \mathrm{B}-$ dependent mechanism. The function of B94 in this context is unknown.

Recent work suggests that NF- $\kappa \mathrm{B}$ has genomic actions, even in the absence of exogenous stimuli. This "constitutive" NF- $\kappa$ B activation may be important to inhibit apoptosis (reviewed in Barkett and Gilmore, 1999). For example, NF- $\kappa$ B appears to be required to maintain low levels of the Bcl-2 protein, A1, at levels 
to prevent loss of mitochondrial transmembrane potential and apoptosis in macrophages (Pagliari et al., 2000). Alternatively, constitutive NF- $\kappa \mathrm{B}$ activity may be important in cellular immortalization (Arsura et al., 2000). Although our experimental design cannot distinguish these or other potential roles for constitutive $\mathrm{NF}-\kappa \mathrm{B}$ activity, we interpret our data to mean that constitutive $\mathrm{NF}-\kappa \mathrm{B}$ appears to downregulate expression of the collagen genes and others. The mechanism (transcriptional or post-transcriptional) by which $N F-\kappa B$ influences the abundance of these genes will require further investigation. In this regard, we note that a recent study has implicated NF- $\kappa \mathrm{B}$ in the post-transcriptional control of MyoD mRNA abundance (Guttridge et al., 2000); perhaps collagen is regulated in a similar way.

\section{Expression Kinetics of the NF-кB-inducible Genetic Network}

We preliminarily analyzed the kinetics of gene expression for the highly upregulated NF- $\kappa \mathrm{B}$-dependent genes taken from Table I. For this analysis, microarray data from our previously established database of RSV infection was taken corresponding to type II-like alveolar epithelial cells (A549) (Zhang et al., 2001) and laryngeal carcinoma cells (Hep2) (B. Tian, unpublished data). A hierarchical clustering/heat map analysis was performed and is presented in Figure 8. In Figure 8A, the A549 time course shows that several of the $\mathrm{NF}-\kappa \mathrm{B}-d e p e n d e n t$ genes exhibit anomalous behavior. For example, an "unknown" gene, cytochrome P (CYP)11B1, melanoma antigen-encoding gene (GAGE)-2, and tyrosine phosphatase were not expressed by A549 cells. In addition, the gene encoding a putative membrane protein was paradoxically regulated, being downregulated by RSV infection in A549 cells. The remaining genes were activated from 6-12 hours after RSV infection, a time when induction of NF- $\kappa \mathrm{B}$ binding can be demonstrated by EMSA and immunofluorescence analysis (Garofalo et al., 1996; Tian et al., 2002). Figure 8B shows a similar analysis for the kinetics of NF- $\kappa \mathrm{B}$-dependent gene induction in Hep2 cells. Like A549 cells, the genes "unknown," p450, and GAGE-2 were not expressed; unlike A549 cells, however, the melanoma growth stimulatory activity/growth-regulated oncogene (MGSA/GRO)- $\alpha$ and cholesterol hydroxylase genes were not expressed in the Hep2 cells. The remaining genes were regulated by RSV infection in a manner quite similar to that seen in A549 (compare Figure $8 \mathrm{~B}$ with $8 \mathrm{~A}$ ). Together, these data indicate that cell type has a strong influence on the composition of a genetic network.

\section{Promoter Analysis of NF- $\kappa \mathrm{B}$-inducible Genes}

The identification of NF- $\kappa \mathrm{B}$-inducible genes allows us to glean insights into the actions of this master regulator of inflammation. That these genes are all 
downstream of the same transcription factor and have similar patterns of expression indicated to us that further analysis of their promoter organizations may yield some unifying insights into the mechanism for NF- $\kappa \mathrm{B}$-dependent gene control. One successful approach to identification of common regulatory sequences has been to analyze empirically groups of promoters based on similarities in expression patterns (Tavazoie et al., 1999; Pilpel et al., 2001). In this example, a K-means algorithm was used to cluster groups of genes whose expression was similar in data derived from cell-cycle progression in Saccharomyces. A local alignment tool identified 17 motifs in 12 different clusters, over half of which corresponded to know DNA-binding sites, suggesting that expression coclustering identifies promoters with common regulatory motifs (Tavazoie et al., 1999). To address whether similarities could be found in the NF- $\kappa \mathrm{B}-$ inducible genes, we retrieved the promoter sequences of the most tightly coclustering expression group (Figures 8A and B). The promoter sequences were annotated and analyzed for the presence of transcription factor-binding sites. Although a number of methods for identifying the presence of transcription factor-binding sites exist, recent algorithms employing positional weight matrices (PWM) have significantly improved the reliability of computational prediction of transcription factor-binding sites. PWMs have improved the accuracy of prediction of specific transcription factor-binding sites by accommodating for the large, base-to-base variability in target binding sites. PWMs assign a weighted score for each nucleotide in the promoter sequence and generate an overall score as the sum of the matrix values. Moreover, the weighted matrix score is related to the Gibbs free energy of binding (Berg and von Hippel, 1987; Stormo, 2000) and therefore has biological significance.

For analysis of factors binding the proximal promoters, binding sites for all eukayrotic transcription factors were predicted using the high-stringency cutoff, to minimize the false positive and negative matches from the TRANSFAC database (Heinemeyer et al., 1999). To correlate these data with experimental determination of binding sites, we compared the TRANSFAC output with our in vitro binding studies on the IL-8 and RANTES promoters. For example, the analysis correctly predicted the known AP-1 (Vlahopoulos et al., 1999) and NF- $\kappa$ B binding sites (Brasier et al., 1998) of the IL-8 gene. Similarly, the known NF-IL6 and NF- $\kappa$ B binding sites from the RANTES promoter were predicted (Casola et al., 2000b). Computer-identified NF- $\kappa$ B binding sites are displayed in Table II. Here, we also searched the literature for previously identified NF- $\kappa$ B binding sites for experimental verification where possible. We were able to confirm the putative NF- $\kappa \mathrm{B}$-binding sites with the published literature for the GRO- $\alpha$ (Wood and Richmond, 1995), IL-8 (Brasier et al., 1998), RANTES (Casola et al., 2000b), IRF-7B (Lu et al., 2002), IAP-1 (Hong et al., 2000), NF- $\kappa$ B2 (Liptay et al., 1994), and IL-15R $\alpha$ (Mariner et al., 2001) promoters. In the other genes, the absence of NF- $\kappa$ B sites may indicate that the binding site is 


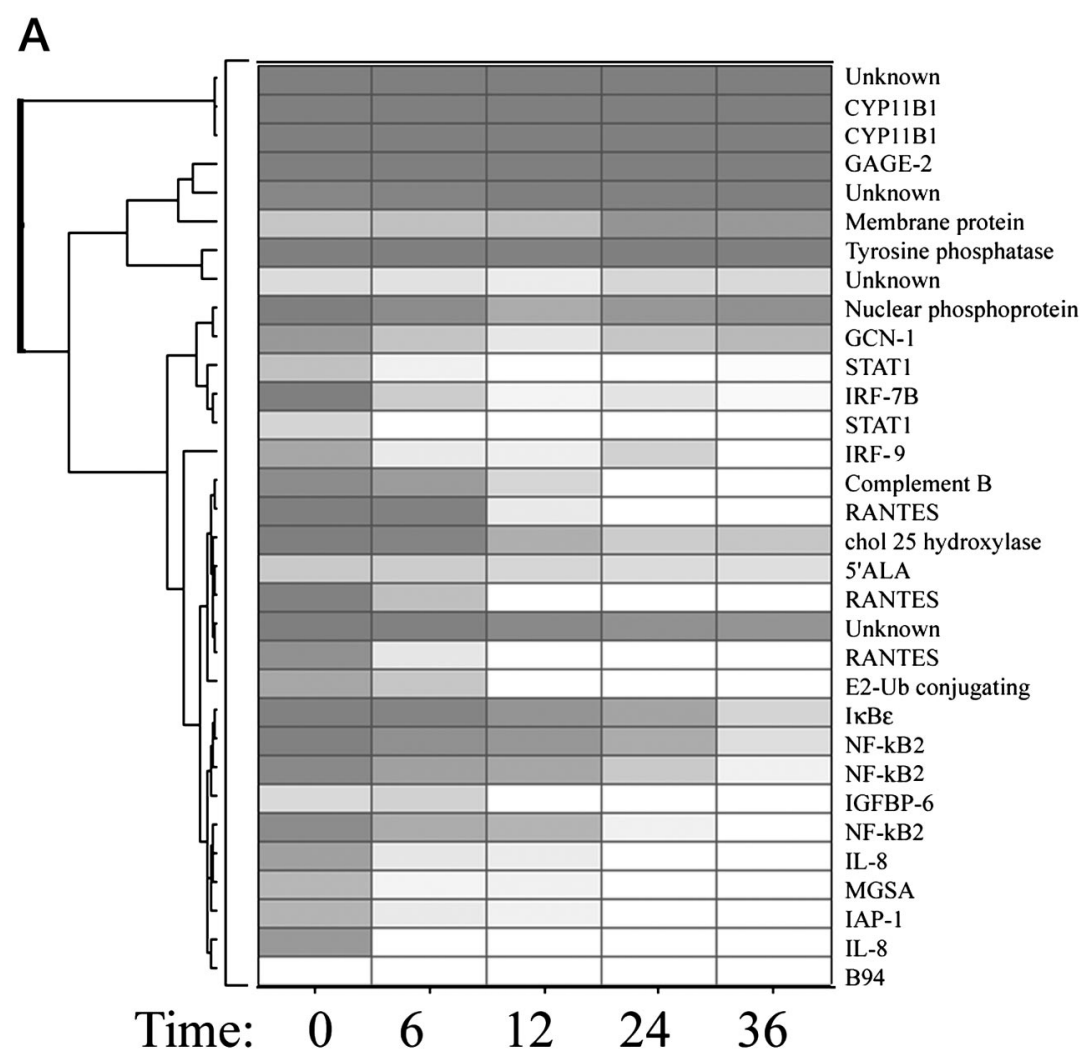

FIG. 8. Kinetics of NF- $\kappa$ B-dependent gene expression in epithelial cells. (A) A549 cells. Clustering and heat map analysis of the kinetics of NF- $\kappa$ B-dependent gene expression in type II-like alveolar cells following RSV infection. Data represent the mean of three independent time courses analyzed by high-density microarrays. Agglomerative hierarchical clustering was performed on average fluorescence intensity values from three independent experiments using the UPGMA technique. A heat map for each gene for the three independent experimental datapoints is shown at right. The color gradient used is dark gray (minimum value of 5 scaled fluorescence intensity units), light gray (middle value of 5000 scaled units), and white (maximum value of 10,000 scaled units). CYP, cytochrome P; GAGE, melanoma antigen-encoding gene; MGSA, melanoma growth stimulatory activity. [Data from Zhang Y, Luxon BA, Casola A, Garofalo RP, Jamaluddin M, Brasier AR 2001 Expression of RSV-induced chemokine gene networks in lower airway epithelial cells revealed by cDNA microarrays. J Virol 75:9044-9058.]

located outside of the $700 \mathrm{bp}$ of $5^{\prime}$ flanking sequence that was analyzed or that the gene is indirectly regulated by NF- $\kappa \mathrm{B}$. More investigation will have to be done to distinguish between these possibilities.

We then analyzed matches for all predicted eukaryotic transcription factorbinding sites using the most stringent cutoffs for matrix similarity score in the 


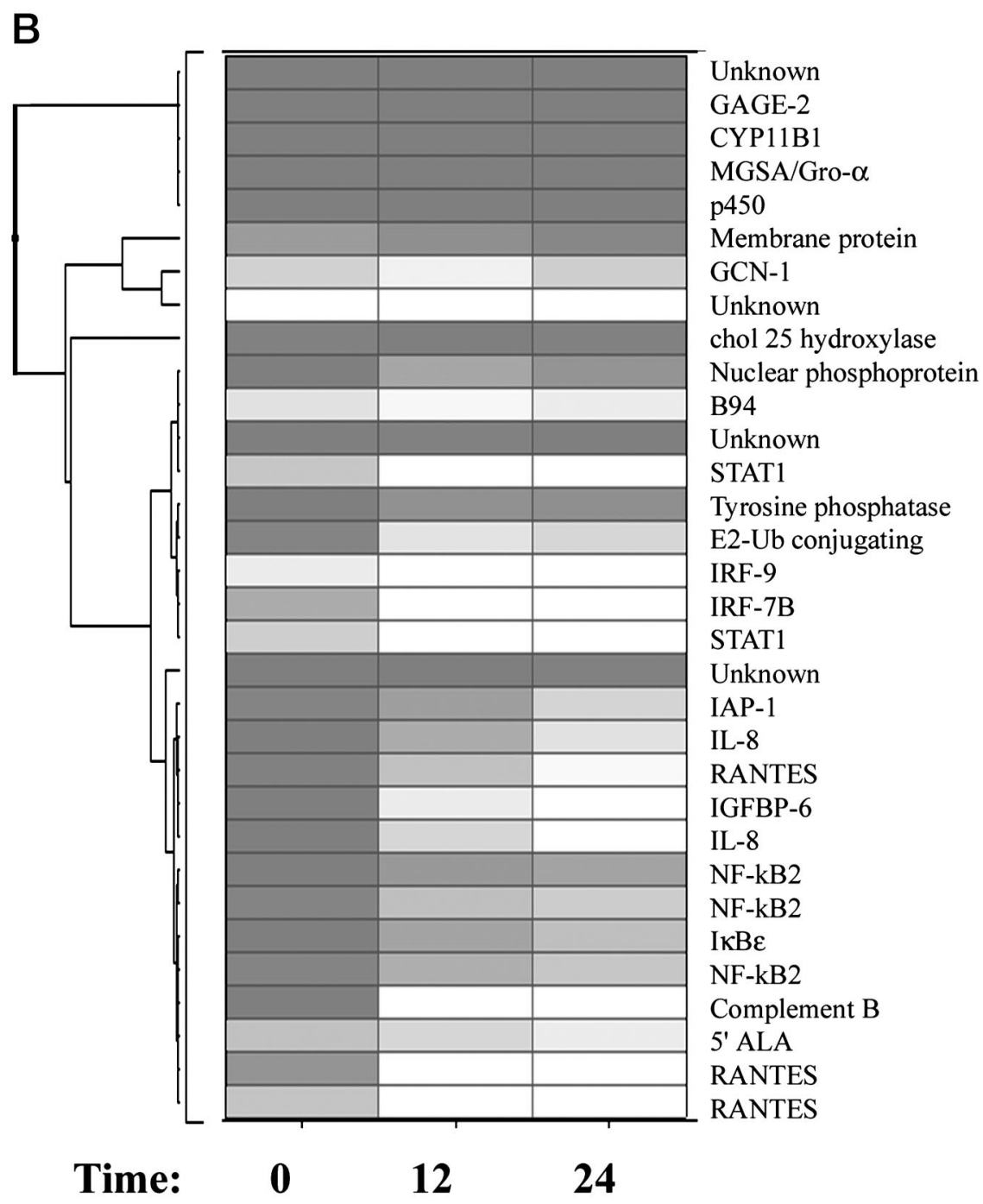

FIG. 8. (B) Hep2 cells. Clustering and heat map analysis of the kinetics of NF- $\kappa$ B-dependent gene expression in Hep2 larygeal carcinoma cells following RSV infection. [Data analysis as in Figure 8A.]

TRANSFAC database. In the sequences analyzed, the predicted binding site density was one transcription factor for approximately every eight base pairs (7.9 \pm 1.8 ). Unfortunately, this density of transcription factor-binding data made it difficult to see relationships between the various promoters. To help identify 
and visualize binding patterns, we developed an interactive, versatile data visualization/mining tool that we call GeneRep. GeneRep displays the location of transcription factor-binding sites as colored rectangles along their linear sequence. The closeness of the match (the "similarity score") is indicated by the height of the rectangle. To help identify the location of the NF- $\kappa \mathrm{B}$ binding sites, they appear as solid black in Figure 9. The NF- $\kappa$ B2, IL-8, IGF-BP6, and Gro- $\alpha$ promoters all contained high-affinity binding sites in the proximal $100 \mathrm{bp}$ of the TATA box. Preliminary analysis did not reveal any consistent relationship of the NF- $\kappa$ B-binding site with binding sites for AP-1, IRF, or NF-IL6. More systematic analysis will be required to identify any common features for this subclass of inducible promoters.

\section{Conclusions}

$\mathrm{NF}-\kappa \mathrm{B}$ is a highly inducible transcription factor that controls hepatic acute-phase response, innate and adaptive immunity, and cellular survival through the induction of genetic networks. We reviewed our work using a high-density microarray analysis of a tightly regulated cell model expressing a specific NF- $\kappa \mathrm{B}$ inhibitor to identify its downstream gene network. Our findings

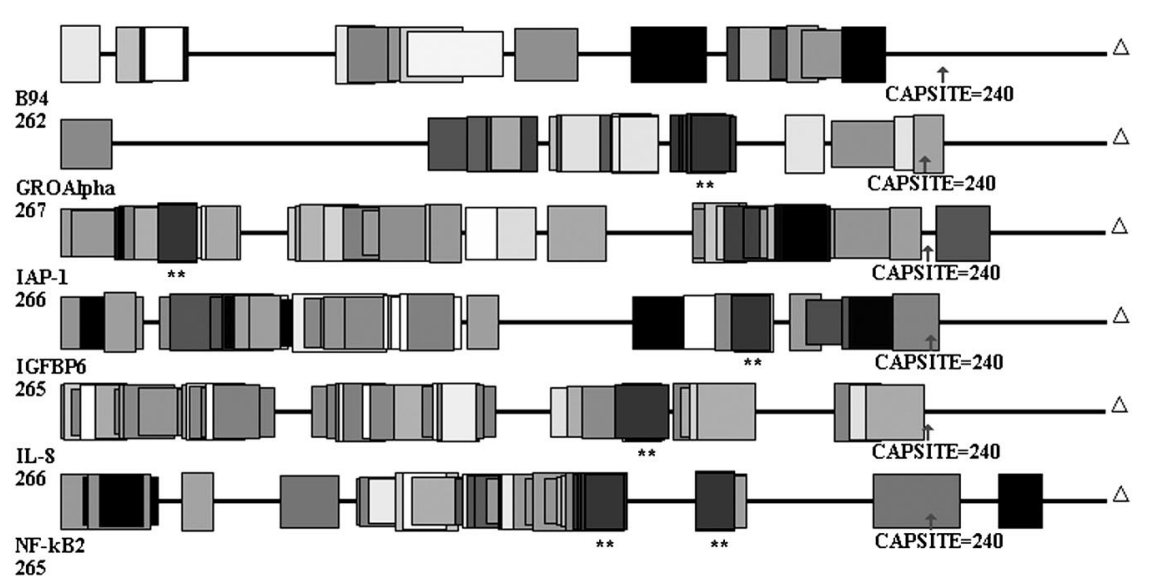

FIG. 9. Promoter analysis of NF- $\kappa \mathrm{B}$-dependent network. Graphical display for NF- $\kappa \mathrm{B}-$ dependent promoter. Transcription factor binding sites are represented by shaded rectangles whose location is dependent upon distance from the transcription start site. The height of the rectangle is directly proportional to the TRANSFAC matrix similarity score, so the significance of the match can be easily determined by visual inspection. The rectangles are shaded, based on the DNA composition for each site. The transcription start site is indicated by a vertical arrow and the location in nucleotides is indicated below each arrow. The high-stringency NF- $\kappa \mathrm{B}$ binding sites are indicated by double asterisks. 
suggest that NF- $\kappa \mathrm{B}$ regulates expression of distinct genetic networks of constitutive genes whose expression are inhibited further by viral infection as well as controlling a distinct subset of those that are viral inducible. Moreover, these data suggest that $\mathrm{NF}-\kappa \mathrm{B}$ is a upstream regulator of RSV-inducible gene expression through controlling expression of the proteins involved in interferon signaling (STAT/IRF), perhaps providing insights into mechanisms of how NF- $\kappa \mathrm{B}$ controls the innate immune response. More work will be required to understand the cell type-specific influences on expression of NF- $\kappa \mathrm{B}$ networks, so that members of this network can be comprehensively identified. Further analysis is required to understand whether a common promoter architecture of an NF- $\kappa \mathrm{B}$-dependent gene can be identified, which genes are indirectly controlled by $\mathrm{NF}-\kappa \mathrm{B}$, and, in these, the mechanisms for this regulation.

\section{ACKNOWLEDGMENTS}

The authors would like to thank M. Gossen and H. Bujard for tTA plasmids (University of Heidelberg) and the University of Texas Medical Branch Genomics Core Laboratory (T. Wood, Director) for performing the arrays. This project was supported by grant R21 AI48163 from the National Institute of Allergy and Infectious Diseases (NIAID) and, in part, by R01 AI40218 (to A.R.B.) and AI 15939 (to R.P.G.), Child Health and Human Development (R30HD 27841), and \#P30 ES06676 from the National Institute of Environmental Health Sciences (to R.S. Lloyd, University of Texas Medical Branch).

\section{REFERENCES}

Alam R, Stafford S, Forsythe P, Harrison R, Faubio d, Lett-Brown MA, Grant JA 1994 RANTES is chemotactic and activating factor for human eosinophils. J Exp Med 179:751756

Arsura M, Mercurio F, Oliver AL, Thorgeirsson SS, Sonenshein GE 2000 Role of the IkappaB kinase complex in oncogenic Ras- and Raf-mediated transformation of rat liver epithelial cells. Mol Cell Biol 20:5381-5391

Baggiolini M, Dewald B, Moser B 1997 Human chemokines: an update. Annu Rev Immunol 15:675-705

Baldwin ASJ 1996 The NF-kappa B and I kappa B proteins: new discoveries and insights. Annu Rev Immunol 14:649-683

Barkett M, Gilmore T 1999 Control of apoptosis by Rel/NF-kB transcription factors. Oncogene 18:6910-6924

Barnes PJ, Karin M 1997 Nuclear factor-kappaB: a pivotal transcription factor in chronic inflammatory diseases. [Review] [53 refs]. N Engl J Med 336:1066-1071

Becskei A, Serrano L 2000 Engineering stability in gene networks by autoregulation. [see comments.]. Nature 405:590-593

Beg AA, Baldwin ASJ 1993 The I kappa B proteins: multifunctional regulators of Rel/NF- kappa B transcription factors. Genes Dev 7:2064-2070

Beg AA, Sha W, Bronson RT, Ghosh S, Baltimore D 1995 Embryonic lethality and liver degeneration in mice lacking the RelA component of NF-kB. Nature 376:167-170

Berg OG, von Hippel PH 1987 Selection of DNA binding sites by regulatory proteins. Statisticalmechanical theory and application to operators and promoters. J Mol Biol 193:723-750 
Berman BP, Nibu Y, Pfeiffer BD, Tomancak P, Celniker SE, Levine M, Rubin GM, Eisen MB 2002 Exploiting transcription factor binding site clustering to identify cis-regulatory modules involved in pattern formation in the Drosophila genome. Proc Natl Acad Sci USA 99:757762

Blobel GA 2000 CREB-binding protein and p300: molecular integrators of hematopoietic transcription. [Review] [167 refs]. Blood 95:745-755

Brasier AR, Li J, Wimbish KA 1996 Tumor necrosis factor activates angiotensinogen gene expression by the Rel A transactivator. J Hypertens 27:1009-1017

Brasier AR, Jamaluddin M, Casola A, Duan W, Shen Q, Garofalo R 1998 A promoter recruitment mechanism for TNF $\alpha$-induced IL- 8 transcription in type II pulmonary epithelial cells: dependence on nuclear abundance of Rel A, NF-kB1 and c-Rel transcription factors. J Biol Chem 273:3551-3561

Brasier AR, Lu M, Hai T, Lu Y, Boldogh I 2001 NF-kB inducible BCL-3 expression is an autoregulatory loop controlling nuclear p50/NF-kB1 residence. J Biol Chem 276:3208032093

Brown K, Gerstberger S, Carlson L, Franzoso G, Siebenlist U 1995 Control of IkB-alpha proteolysis by site-specific, signal-induced phosphorylation. Science 267:1485-1488

Bussemaker HJ, Li H, Siggia ED 2001 Regulatory element detection using correlation with expression. Nat Genet 27:167-171

Cao Z, Xiong J, Takeuchi M, Kurama T, Goeddel DV 1996 TRAF6 is a signal transducer for interleukin-1. Nature 383:443-446

Cardozo AK, Heimberg H, Heremans Y, Leeman R, Kutlu B, Kruhoffer M, Orntoft T, Eizirik DL 2001 A comprehensive analysis of cytokine-induced and nuclear factor-kappa Bdependent genes in primary rat pancreatic beta -cells. J Biol Chem 276:48879-48886

Carey M 1998 The enhanceosome and transcriptional synergy. [Review] [20 refs]. Cell 92:5-8

Casola A, Garofalo R, Jamaluddin M, Vlahopoulos S, Brasier AR 2000a Requirement of a novel upstream response element in respiratory syncytial virus-induced IL-8 gene expression. J Immunol 164:5944-5951

Casola A, Garofalo RP, Haeberle H, Elliott T, Jamaluddin M, Brasier AR 2000b Multiple inducible cis elements control RANTES promoter activation in alveolar epithelial cells infected with RSV. J Virol 75:6428-6439

Casola A, Burger N, Liu T, Jamaluddin M, Brasier AR, Garofalo RP 2001 Oxidant tone regulates RANTES gene expression in airway epithelial cells infected with RSV. J Biol Chem 276:19715-19722

Everard ML, Swarbrick A, Wrightham M, McIntyre J, Dunkley C, James PD, Sewell HF, Milner AD 1994 Analysis of cells obtained by bronchial lavage of infants with respiratory syncytial virus infection. Arch Dis Child 71:428-432

Gabbitas B, Canalis E 1997 Growth factor regulation of insulin-like growth factor binding protein-6 expression in osteoblasts. J Cell Biochem 66:77-86

Garofalo R, Kimpen JLL, Welliver RC, Ogra PL 1992 Eosinophil degranulation in the respiratory tract during naturally acquired respiratory syncytial virus infection. J Pediatr 120:28-32

Garofalo R, Dorris A, Ahlstedt S, Welliver R 1994 Peripheral blood eosinophil counts and eosinophil cationic protein content of respiratory secretions in bronchiolitis: relationship to severity of disease. Pediatr Allergy Immunol 5:111-117

Garofalo R, Sabry M, Jamaluddin M, Yu RK, Casola A, Ogra PL, Brasier AR 1996 Transcriptional activation of the interleukin-8 gene by RSV infection in alveolar epithelial cells: nuclear translocation of the Rel A transcription factor as a mechanism producing airway mucosal inflammation. J Virol 70:8773-8781 
Geiser T, Dewald B, Ehrengruber MU, Clark-Lewis I, Baggiolini M 1993 The interleukin-8 related chemotactic cytokines GRO $\alpha, \operatorname{GRO} \beta$ and GRO $\gamma$ activate human neutrophil and basophil leukocytes. J Biol Chem 268:15419-15424

Gossen M, Bujard H 1992 Tight control of gene expression in mammalian cells by tetracyclineresponsive promoters. Proc Natl Acad Sci USA 89:5547-5551

Guttridge DC, Mayo MW, Madrid LV, Wang CY, Baldwin AS Jr 2000 NF-kappaB-induced loss of MyoD messenger RNA: possible role in muscle decay and cachexia. [see comments]. Science 289:2363-2366

Haeberle H, Takizawa R, Casola A, Brasier AR, Dieterich H-J, vanRooijen N, Gatalica Z, Garofalo RP 2002 Respiratory syncytial virus-induced activation of NF-kappaB in the lung involves alveolar macrophages and toll-like receptor 4-dependent pathways. J Infect Dis 186:1199-1206

Han Y, Brasier AR 1997 Mechanism for biphasic Rel A:NF-kB1 nuclear translocation in tumor necrosis factor $\alpha$-stimulated hepatocytes. J Biol Chem 272:9823-9830

Han Y, Meng T, Murray NR, Fields AP, Brasier AR 1999a IL-1 Induced NF-kB-IkBa autoregulatory feedback loop in hepatocytes: a role for $\mathrm{PKCa}$ in post-transcriptional regulation of IkBa resynthesis. J Biol Chem 274:939-947

Han Y, Weinman SA, Boldogh S, Brasier AR 1999b TNF $\alpha$-Inducible I $\kappa$ B $\alpha$ Proteolysis and NF- $\kappa$ B activation mediated by cytosolic m-calpain. J Biol Chem 274:787-794

Heinemeyer T, Chen X, Karas H, Kel AE, Kel OV, Liebich I, Meinhardt T, Reuter I, Schacherer F, Wingender E 1999 Expanding the TRANSFAC database towards an expert system of regulatory molecular mechanisms. Nucleic Acids Res 27:318-322

Henkel T, Machleidt T, Alkalay I, Kronke M, Ben-Neriah Y, Baeuerle PA 1993 Rapid proteolysis of I kappa B-alpha is necessary for activation of transcription factor NF-kappa B. Nature 365:182-185

Hong S-Y, Yoon W-H, Park J-H, Kang SG, Ahn J-H, Lee TH 2000 Involvement of two NF-kB binding elements in tumor necrosis factor $\alpha, \mathrm{CD} 40$, and Epstein-Barr virus latent membrane protein 1-mediated induction of the cellular inhibitor of apoptosis protein 1 gene. J Biol Chem 275:18022-18028

Hsu H, Huang J, Shu HB, Baichwal V, Goeddel DV 1996 TNF-dependent recruitment of the protein kinase RIP to the TNF receptor-1 signaling complex. Immunity 4:387-396

Jamaluddin M, Casola A, Garofalo RP, Han Y, Elliott T, Ogra PL, Brasier AR 1998 The major component of IkBa proteolysis occurs independently of the proteasome pathway in respiratory syncytial virus-infected pulmonary epithelial cells. J Virol 72:4849-4857

Jamaluddin M, Meng T, Sun J, Boldogh I, Han Y, Brasier AR 2000 Angiotensin II induces nuclear factor (NF)-kappaB1 isoforms to bind the angiotensinogen gene acute-phase response element: a stimulus-specific pathway for NF-kappaB activation. Mol Endocrinol 14:99-113

Jones KA, Kadonaga JT 2000 Exploring the transcription-chromatin interface. Genes Dev 14:19921996

Karin M 1999 The beginning of the end: IkB kinase (IKK) and NF-kB activation. J Biol Chem 274:27342

Karin M, Ben Neriah Y 2000 Phosphorylation meets ubiquitination: the control of NF- $\kappa$ B activity. [Review] [235 refs]. Annu Rev Immunol 18:621-663

Kelliher MA, Grimm S, Ishida Y, Kuo F, Stanger BZ, Leder P 1998 The death domain kinase RIP mediates the TNF-induced NF-kappa B signal. Immunity 8:297-303

Korzus E, Torchia J, Rose DW, Xu L, Kurkawa R, McInerney EM, Mullen T-M, Glass CK, Rosenfeld MG 1998 Transcription factor-specific requirements for coactivators and their acetyltransferase functions. Science 279:703-707 
Kunsch C, Ruben SM, Rosen CA 1992 Selection of optimal kB/Rel DNA-binding motifs: interaction of both subunits of NF-kB with DNA is required for transcriptional activation. Mol Cell Biol 12:4412-4421

Li J, Brasier AR 1996 Angiotensinogen gene activation by AII is mediated by the Rel A (NF-kB p65) transcription factor: one mechanism for the renin angiotensin system (RAS) positive feedback loop in hepatocytes. Mol Endocrinol 10:252-264

Liptay S, Schmid RM, Nabel EG, Nabel GJ 1994 Transcriptional regulation of NF-kB2: evidence for kB-mediated positive and negative autoregulation. Mol Cell Biol 14:7695-7703

Lu R, Moore PA, Pitha PM 2002 Stimulation of IRF-7 gene expression by tumor necrosis factor alpha: requirement for NF-kB transcription factor and gene accessibility. J Biol Chem 277:16592-16598

Malanin NL, Boldin MP, Kovalenko AV, Wallach D 1997 MAP3K-related kinase involved in NF-kB induction by TNF, CD95 and IL-1. Nature 385:540-544

Mariner JM, Lantz V, Waldmann TA, Azimi N 2001 Human T cell lymphotropic virus type I Tax activates IL-15Ra gene expression through an NF-kB site. J Immunol 166:2609

Marton MJ, Vazques de Aldana CR, Qium H., Chakraburtty K, Hinnebusch AG 1997 Evidence that GCN1 and GCN20, translational regulators of GCN4, function on elongating ribosome in activation of eIF2 alpha kinase GCN2. Mol Cell Biol 17:4474-4489

Matsushima K, Oppenheim JJ 1989 Interleukin 8 and MCAF: novel inflammatory cytokines inducible by IL-1 and TNF. Cytokine 1:2-33

McKnight SL, Yamamoto KR 1992 Transcriptional Regulation. Cold Spring Harbor, NY: Cold Spring Harbor Laboratory Press

Munshi N, Merika M, Yie J, Senger K, Chen G, Thanos D 1998 Acetylation of HMG I(Y) by CBP turns off IFNb expression by disrupting the enhanceosome. Molecular Cell 2:457-467

Murphy PM 1994 The molecular biology of leukocyte chemoattractant receptors. Annu Rev Immunol 12:593-633

Na S-Y, Lee S-K, Han S-J, Choi H-S, Im S-Y, Lee J-W 1998 Steroid receptor coactivator-1 interacts with the p50 subunit and coactivates nuclear factor kB-mediated transactivations. J Biol Chem 273:10831-108334

Ndubuisi M, Guo G, Fried V, Etlinger J, Sehgal P 1999 Cellular physiology of STAT3: where's the cytoplasmic monomer? J Biol Chem 274:25509

Ninomiya-Tsuhi J, Kishimoto K, Hiyama A, Inoue J-I, Cao Z, Matsumoto K 1999 The kinase TAK1 can activate the NIK-IkB as well as the MAP kinase cascade in the Il-1 signalling pathway. Nature 398:252-256

Nonaka M, Huang ZM 1990 Interleukin-1 mediated enhancement of mouse factor B gene expression via NF-kB like hepatoma nuclear factor. Mol Cell Biol 10:6283-6289

Oppenheim JJ, Zachariae COC, Mukaida N, Matsushima K 1991 Properties of the novel proinflammatory supergene 'intercrine' cytokine family. Annu Rev Immunol 9:617-648

Pagliari LJ, Perlman H, Liu H, Pope RM 2000 Macrophages require constitutive NF-kappaB activation to maintain A1 expression and mitochondrial homeostasis. Mol Cell Biol 20:88558865

Perkins ND, Felzien LZ, Betts JC, Leung K, Beach DH, Nabel GJ 1997 Regulation of NF-kB by cyclin-dependent kinases associated with the p300 coactivator. Science 275:523-527

Pilpel Y, Sudarsanam P, Church GM 2001 Identifying regulatory networks by combinatorial analysis of promoter elements. [see comments.]. Nat Genet 29:153-159

Poyet J-L, Srinivasula SM, Lin J-H, Fernandes-Alnemri T, Yamaoka S, Tsichlis PN, Alnemri ES 2000 Activation of the IkB kinases by RIP via IKKg/NEMO-mediated oligomerization. J Biol Chem 275:37966-37977

Ruuskanen O, Ogra PL 1993 Respiratory syncytial virus. Curr Prob Pediat 2:50-79 
Saccani S, Pantano S, Natoli G 2001 Two waves of nuclear factor kB recruitment to target promoters. J Exp Med 193:1351-1359

Sarma V, Wolf FW, Marks RM, Shows TB, Dixit VM 1992 Cloning of a novel tumor necrosis factor-alpha-inducible primary response gene that is differentially expressed in development and capillary tube-like formation in vitro. J Immunol 148:3302-3312

Schindler C, Darnell JE Jr 1995 Transcriptional response to polypeptide ligands: the JAK-STAT pathway. Annu Rev Biochem 64:621-651

Schmid RM, Perkins ND, Duckett CS, Andrews PC, Nabel GJ 1991 Cloning of an NF-kappa B subunit which stimulates HIV transcription in synergy with p65. Nature 352:733-736

Shay DK, Holman RC, Newman RD, Liu LL, Stout JW, Anderson LJ 1999 Bronchiolitisassociated hospitalizations among US children, 1980-1996. JAMA 282:1440-1446

Shay DK, Holman RC, Roosevelt GE, Clarke MJ, Anderson LJ 2001 Bronchiolitis-associated mortality and estimates of respiratory syncytial virus-associated deaths among US children, 1979-1997. J Infect Dis 183:16-22

Siebenlist U, Franzoso G, Brown K 1994 Structure, regulation and function of NF-kB. Annu Rev Cell Biol 10:405-455

Springer T 1994 Traffic signals for lymphocyte recirculation and leukocyte emigration: the multiple paradigm. Cell 76:301

Stormo GD 2000 DNA binding sites: representation and discovery. Bioinformatics 16:16-23

Taniguchi T, Ogasawara K, Takaoka A, Tanaka N 2001 IRF family of transcription factors as regulators of host defense. [Review] [189 refs]. Annu Rev Immunol 19:623-655

Tavazoie S, Hughes JD, Campbell MJ, Cho RJ, Church GM 1999 Systematic determination of genetic network architecture. Nat Genet 22:281-285

Teran LM, Noso N, Carroll M 1996 Eosinophil recruitment following allergen challenge is associated with the release of the chemokine RANTES into asthmatic airways. J Immunol 157:1806-1812

Thanos D, Maniatis T 1995 Virus induction of human IFN beta gene expression requires the assembly of an enhanceosome. Cell 83:1091-1100

Thomas LH, Friedland JS, Sharland M, Becker S 1998a Respiratory syncytial virus-induced RANTES production from human bronchial epithelial cells is dependent on nuclear factorkappa B nuclear binding and is inhibited by adenovirus-mediated expression of inhibitor of kappa B alpha. J Immunol 161:1007-1016

Thomas LH, Friedland JS, Sharland M, Becker S 1998b Respiratory syncytial virus-induced RANTES production from human bronchial epithelial cells is dependent on nuclear factor-kB binding and is inhibited by adenovirus-mediated expression of inhibitor of $\mathrm{kBa}$. $\mathrm{J}$ Immunol 161:1007-1016

Tian B, Zhang Y, Luxon BA, Garofalo RP, Casola A, Sinha M, Brasier AR 2002 Identification of NF- $\kappa \mathrm{B}$ dependent gene networks in respiratory syncytial virus-infected cells. J Virol 76:6800-6814

Vlahopoulos S, Boldogh I, Brasier AR 1999 NF- $\kappa$ B dependent induction of interleukin-8 gene expression by tumor necrosis factor $\alpha$ : evidence for an antioxidant sensitive activating pathway distinct from nuclear translocation. Blood 94:1878-1889

Wadgaonkar R, Phelps KM, Haque Z, Williams AJ, Silverman ES, Collins T 1999 CREB binding protein is a nuclear integrator of nuclear factor-kB and p53 signaling. J Biol Chem 274:1879-1882

Wang C, Deng L, Hong M, Akkaraju GR, Inoue J, Chen ZJ 2001 TAK1 is a ubiquitin-dependent kinase of MKK and IKK [see comments]. Nature 412:346-351

Wood LD, Richmond A 1995 Constitutive and cytokine-induced expression of the melanoma growth stimulatory activity/GRO alpha gene requires both NF-kappa B and novel constitutive factors. J Biol Chem 270:30619-30626 
Yie J, Merika M, Munshi N, Chen G, Thanos D 1999a The role of HMG I(Y) in the assembly and function of the IFN-beta enhanceosome. EMBO J 18:3074-3089

Yie J, Senger K, Thanos D 1999b Mechanism by which the IFN-beta enhanceosome activates transcription. Proc Nat Acad Sci USA 96:13108-13113

Zhang G, Ghosh S 2001 Toll-like receptor-mediated NF-kB activation: a phylogenetically conserved paradigm in innate immunity. J Clin Invest 107:13-19

Zhang SQ, Kovalenko A, Cantarella G, Wallach D 2000 Recruitment of the IKK signalosome to the p55 TNF receptor: RIP and A20 bind to NEMO (IKKgamma) upon receptor stimulation. Immunity 12:301-311

Zhang Y, Luxon BA, Casola A, Garofalo RP, Jamaluddin M, Brasier AR 2001 Expression of RSV-induced chemokine gene networks in lower airway epithelial cells revealed by cDNA microarrays. J Virol 75:9044-9058 